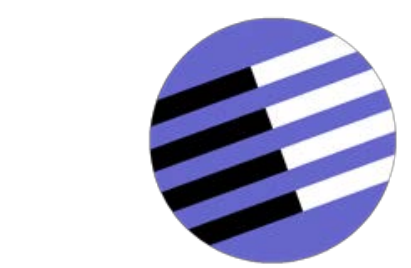

GOVERNANCE AND THE EFFICIENCY

OF ECONOMIC SYSTEMS

G E S Y

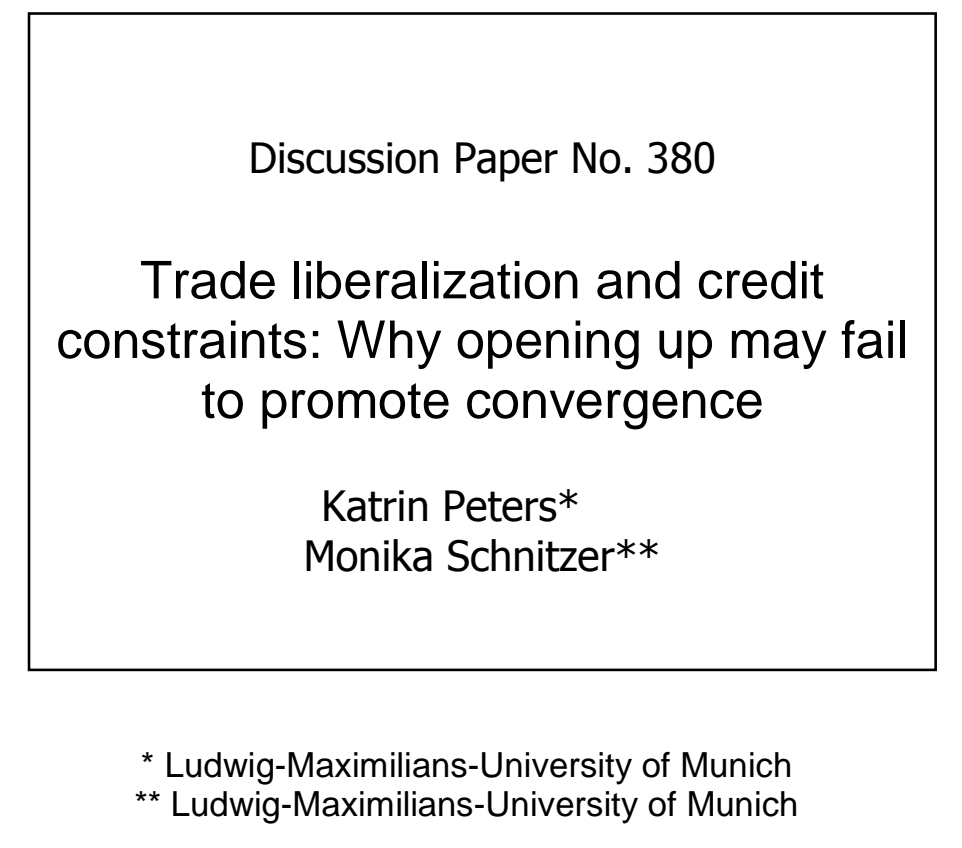

April 2012

Financial support from the Deutsche Forschungsgemeinschaft through SFB/TR 15 is gratefully acknowledged. 


\title{
Trade liberalization and credit constraints: Why opening up may fail to promote convergence *
}

\author{
Katrin Peters ${ }^{\dagger}$ and Monika Schnitzer ${ }^{\ddagger}$
}

April 2012

\begin{abstract}
Recent evidence suggests that despite opening up a country for trade, the productivity gap between developed and emerging economies often does not close. This paper examines credit constraints as one channel held responsible for hampering convergence. Specifically, we extend a Melitz and Ottaviano (2008) type trade model with variable mark-ups to allow for endogenous technology adoption. We consider a framework with two countries that potentially differ with respect to credit market development. Firms have the option to adopt a more efficient technology by paying some fixed cost. A fraction of the fixed technology adoption cost has to be financed externally: in a less developed credit market, the costs of external finance and thus the total costs of technology adoption are higher. A reduction in trade costs raises demand abroad (pro technology-adoption effect) but reduces demand at home because of import competition (anti technology-adoption effect). We find that trade liberalization increases economic performance, that is average productivity and technology adoption, in both countries but that the productivity gap widens. Simulations show that the welfare gap widens too. Opening up without sufficient access to external funding thus fails to promote convergence.
\end{abstract}

JEL classification: F1, O33, O16

Keywords: Trade liberalization, Technology adoption, Financial constraints, Convergence, Productivity gap.

\footnotetext{
*We would like to thank Kalina Manova and Theo Eicher for helpful comments and suggestions. Financial support by the German Science Foundation through GRK 801 and SFB/TR 15 is gratefully acknowledged.

${ }^{\dagger}$ Department of Economics, University of Munich, Akademiestr. 1/III, 80799 Munich, Germany, e-mail: Katrin.Peters@lrz.uni-muenchen.de.

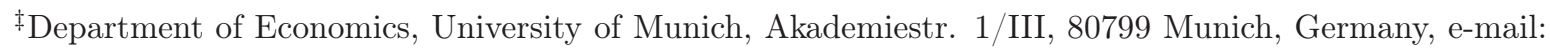
schnitzer@lrz.uni-muenchen.de.
} 


\section{Introduction}

Trade liberalization is one of the most common policy reforms recommended to emerging countries in order to enhance economic development and close the productivity gap towards more developed countries (Rodrik, 2006). Opening up to trade increases the market size for exporters and stimulates investment in advanced technologies. Furthermore, incoming foreign firms foster competition and contribute to a more efficient allocation of resources across firms. However, trade liberalization alone is not enough to ensure economic convergence. A leading example is the North American Free Trade Agreement (NAFTA) between developed countries, the USA and Canada, and a developing country, Mexico, in 1994. In the decade following NAFTA, GDP, exports and investment in Mexico increased but productivity disparities with respect to Canada and the USA did not diminish. One key constraint to achieving convergence have been deficiencies in local credit markets. While large firms have access to foreign financing, inadequate access to domestic credit prevents the vast majority of firms, especially smaller and newer ones, from taking full advantage of the opportunities offered by NAFTA (Lederman et al., 2005).

This paper explores credit constraints as one channel through which trade liberalization might impede convergence between countries. We develop a heterogeneous-firm model of international trade where firms decide whether or not to invest in a more efficient production technology. More specifically, we introduce technology adoption into the Melitz and Ottaviano (2008) framework. A fraction of the cost of purchasing/renting the advanced technology has to be financed externally. Therefore, the technology adoption decision is related to credit market development. In particular, weak protection of creditor rights increases the risk premium creditors require in order to break even in expected terms. We then analyze the effects of trade liberalization on technology adoption, average productivity and welfare in a two-country setting where the two countries potentially differ with respect to credit market development.

We find that the fraction of firms adopting the advanced technology increases with trade liberalization in both countries. In addition to the reallocation of output towards more productive firms (selection effect of trade), there is thus a second source of productivity gains. Technology upgrading and the reallocation of resources lead to higher average productivity and welfare, as in Bustos (2011). However, if firms in one country face credit constraints, the difference between the two countries with respect to the fraction of firms adopting the advanced technology increases. Hence, productivity gains both through firm selection and through technology adoption are lower. As a result, the increase in average productivity in the country with a less developed credit market is lower: the productivity gap widens. 
Simulations show that the welfare gap between the two countries widens too.

This result has important policy implications. Unconditional trade liberalization that reduces trade barriers without improving access to domestic credit fails to promote economic convergence. First, credit constraints lead to a lower selection effect. Second, and more importantly, credit constraints impact negatively on firms' productivity gains from trade liberalization. These firm-level productivity gains capture dynamic gains from trade and are considered more important for long-term growth and convergence than the static gains from resource reallocation (Lederman et al., 2005; Jaramillo and Lederman, 2006).

Our paper contributes to the literature by being, as far as we know, the first to analyze in a theoretical model how credit constraints change the effects of opening up to trade on technology upgrading, average productivity and welfare. Our model with credit constraints draws a nuanced picture of the impact of trade liberalization on economic performance and convergence. Studying trade liberalization between two countries that differ in their credit market development we show that the financially less developed country gains through the reallocation of output towards more productive firms and a higher fraction of firms using the advanced technology. The resulting increase in average productivity, together with an increase in imported products, leads to more product variety and lower prices. However, inadequate access to credit prevents firms from taking full advantage of the larger export market while facing severe import competition, in contrast to firms in the country with a more developed credit market. Thus, while the economy as a whole becomes more affluent, the competitiveness of the corporate sector relative to the more developed country declines. These findings match empirical evidence from NAFTA: after the free trade agreement, Mexico increased its GDP and its exports. However, due to institutional gaps, in particular credit market development, the productivity gap with respect to the USA and Canada did not close.

One advantage of our framework is that it captures both features of trade liberalization, more export opportunities and increased import competition, in a direct way, by using a heterogeneous-firm framework with endogenous mark-ups, without reducing tractability compared to the standard constant-mark-up setup à la Melitz (2003). Consistent with empirical evidence (e.g. Impullitti and Licandro, 2011; Feenstra and Weinstein, 2010; Tybout, 2003), endogenous mark-ups enable us to model the selection effect of trade liberalization through increased import competition. This allows us to capture in a very intuitive way the notion that credit constraints create asymmetries in the way firms benefit from improved export opportunities, are hit by increased import competition, and may thus be more or less inclined to invest in new technologies.

Our analysis builds on and contributes to two strands of the literature. First, it is related 
to previous research that examines the impact of trade liberalization on firm productivity. Bernard et al. (2007) show that in the presence of heterogeneous firms, trade liberalization induces larger productivity gains in comparative advantage industries. In our model, reallocation forces are also larger in countries that have a comparative advantange in the financially dependent sector. In addition, a reduction in trade barriers entails a second, empirically important, asymmetry : the difference in the fraction of advanced technology users increases as well. Bustos (2011) and Navas-Ruiz and Sala (2007) introduce an endogenous technology adoption decision into a Melitz (2003) framework with symmetric countries. ${ }^{1}$ Both papers show that technology adoption increases after trade liberalization, leading to an increase in average productivity in addition to the selection effect of trade. In contrast to these papers, we explicitly consider the financing of technology adoption and allow for firms to be financially constrained. We show that this has important implications for economic convergence. While technology adoption still increases in both countries after trade liberalization, credit constraints prevent the financially less developed country from speeding up convergence. ${ }^{2}$

The second strand of the literature documents the negative impact of financial constraints on firms' ability to invest in innovation. Information asymmetry between firm and creditor, moral hazard problems and lack of collateral reduce the access to external finance for investments in innovative activities (e.g. Hall and Lerner, 2009). The limited access to external finance is likely to result in credit constraints if the credit market is not sufficiently developed. Potential credit market frictions in emerging countries are manifold (Levine, 2005). First, the credit market is often not sufficiently competitive allowing creditors to charge lending rates that largely exceed marginal costs of financing credit. Second, employees without adequate managerial skills and business ethics might increase monitoring costs and lay the foundation for rent-seeking behavior. Moreover, a lack of "Basel Accords" -type recommendations reduces transparency and increases information and transaction costs. Finally, the legal environment in emerging countries often hampers financial contractibility and thereby increases the costs of external finance (e.g. Manova, 2010). Alleviating financing constraints of innovators therefore significantly boosts investment in more advanced technologies (for a theoretical model see e.g. Keuschnigg and Ribi, 2010, for empirical evidence see e.g. Hajivassiliou and Savignac, 2007). Finally, our paper is related to Gorodnichenko and Schnitzer (2012) who analyze the effect of financial constraints on the relation between exporting and innovation using BEEPS data. They argue that exporting and technology adoption are natural complements but when internal funds are limited and external finance is costly, they

\footnotetext{
${ }^{1}$ Unel (2011) extends the Bustos framework to allow for asymmetric countries, with ambiguous results.

${ }^{2}$ Another strand of literature analyzes the dynamic interaction between exporting and innovation activities (e.g. Atkeson and Burstein, 2010; Constantini and Melitz, 2008).
} 
find that engaging in one activity increases the costs of financing the other, and hence that the joint observation of both exporting and innovation becomes less likely.

The paper is organized as follows: Section 2 presents the model setup. The equilibrium is described in Section 3. Section 4 analyzes the impact of trade liberalization and implications for welfare are discussed in Section 5. Section 6 concludes.

\section{The Model}

In this section, we develop a model of the decision to export and to adopt an advanced technology in the presence of credit constraints. In the model, firms are heterogeneous as in Melitz and Ottaviano (2008), and have the option to decrease their production cost by investing in technology adoption, as in Bustos (2011). The costs of technology adoption depend on credit market frictions. We consider two countries that potentially differ with respect to credit market development. Variables of the foreign country, if different from the variables of the home country, are denoted with a star.

\subsection{Setup of the Model}

Preferences. Each country consists of $S$ consumers who have identical preferences over a continuum of varieties indexed by $i \in \Omega$ and a homogeneous good chosen as numéraire and indexed by $0\left(p_{0}=1\right)$. Preferences are described by the quasi-linear quadratic utility function developed by Ottaviano, Tabuchi, and Thisse (2002):

$$
U=q_{0}^{c}+\alpha \int_{i \in \Omega} q_{i}^{c} d i-\frac{1}{2} \gamma \int_{i \in \Omega}\left(q_{i}^{c}\right)^{2} d i-\frac{1}{2} \beta\left(\int_{i \in \Omega} q_{i}^{c} d i\right)^{2},
$$

where $\alpha, \beta, \gamma>0 . q_{0}^{c}$ and $q_{i}^{c}$ denote the per capita consumption level of the homogeneous good and of each variety $i$. The parameters $\alpha$ and $\beta$ characterize substitution between the differentiated good and the numéraire good. The demand for differentiated varieties relative to the numéraire increases as $\alpha$ increases or $\beta$ decreases. The degree of product differentiation is captured by the parameter $\gamma$. If $\gamma=0$, varieties are perfectly substitutable and consumers only care about their overall consumption level $Q^{c}=\int_{i \in \Omega} q_{i}^{c} d i$. As $\gamma$ increases, consumers increasingly prefer to distribute consumption across varieties. A price increase entails thus a smaller drop in demand.

Utility maximization is with respect to the budget constraint $I^{c}=\int_{i \in \Omega^{\prime}} p_{i} q_{i}^{c}+q_{0}^{c}$ where $I^{c}$ is consumer's income. $\Omega^{\prime} \subset \Omega$ denotes the subset of varieties that are consumed in the economy. Assuming that the demand for the numéraire good is positive $\left(q_{0}^{c}>0\right)$, the demand 
for variety $i$ is given by

$$
q_{i} \equiv S q_{i}^{c}=\frac{\alpha S}{\gamma+\beta N}-\frac{S}{\gamma} p_{i}+\frac{\beta N}{\gamma+\beta N} \frac{S}{\gamma} \bar{p}
$$

$\bar{p}=(1 / N) \int_{i \in \Omega^{\prime}} p_{i} d i$ is the average price and $N$ the number of consumed varieties. Variety $i$ is consumed whenever the price $p_{i}$ is non-prohibitive:

$$
p_{i} \leq p_{\max } \equiv \frac{\gamma \alpha}{\gamma+\beta N}+\frac{\beta N}{\gamma+\beta N} \bar{p}
$$

where $p_{\max }$ is the prohibitive price above which demand $q_{i}$ is equal to zero. Equations (2) and (3) then imply a price elasticity of demand equal to

$$
\epsilon_{i}=\left(\frac{p_{\max }}{p_{i}}-1\right)^{-1}
$$

Given the price $p_{i}$, an increase in competition - a larger set of consumed varieties $N$ or a lower average price $\bar{p}$ - raises the price elasticity $\epsilon_{i}$ and decreases the mark-up, $\mu_{i}=$ $\epsilon_{i} /\left(\epsilon_{i}-1\right)$. The mechanism behind this result is the following: an additional variety reduces overall per-variety consumption and leads to a lower prohibitive price. The price elasticity increases and mark-ups decrease. Likewise, a lower price index $\bar{p}$, implying a higher relative price $p_{i} / \bar{p}$, reduces demand for variety $i$ and thereby the mark-up $\mu_{i}$.

Hence, in contrast to the case of a CES demand function, higher product market competition leads to lower mark-ups when using the linear demand system specified in (2).

Supply. The only factor of production, labor, is inelastically supplied in a competitive market. The market for the homogeneous good is perfectly competitive. Firms produce at constant returns to scale and require one unit of labor to produce one unit of output. Assuming a positive demand for the numéraire, the quasi-linear utility in (1) ensures labor market equilibrium. Moreover, the nominal wage in each economy is then equal to unity. ${ }^{3}$ Firms in the differentiated good industry operate under monopolistic competition and take the average price $\bar{p}$ and the number of competitors $N$ as given. Production is at constant returns to scale with firm-specific labor requirement $c_{i}$. The parameter $c_{i}$ thus reflects cost differences across firms. In order to satisfy demand $q_{i}$, firms need to hire $l_{i}=c_{i} q_{i}$ units of labor. In the following, we omit the subscript $i$ for readability.

Entry requires a fixed investment $f_{E}$. This investment is thereafter sunk and captures startup costs such as setting up a facility and buying equipment. Upon entry, firms draw their

\footnotetext{
${ }^{3} q_{0}^{c}>0$ is satisfied if $\beta$ is large enough. We make this assumption in the following.
} 
production cost from a common distribution $G(c)$. When learning the cost of production, firms decide (i) whether to exit the industry or to stay and produce and if they produce (ii) whether to export and whether to invest in technology adoption.

Technology adoption. In our extension of the Melitz and Ottaviano (2008) framework, firms have the option of upgrading their technology by spending $f$ units of labor. The technology adoption cost $f$ can be thought of as a per-period fixed cost that comes with adopting the more advanced technology as for example the rent for new machinery or the periodized purchasing cost. One way to think about technology upgrading is that it reduces production cost by a fixed amount $t$ : firms adopt a process innovation that reduces labor input requirement to $l=(c-t) q \cdot{ }^{4}$ We call $t$ the "technological leap." The advanced technology thus comes at a higher fixed cost but increases productivity. ${ }^{5}$

Credit constraints. The fixed cost of adopting the more advanced technology is paid upfront and cannot be covered by future revenues. Internal funds are not sufficient to cover the investment and firms need to raise outside finance for a fraction $d, d \in[0,1)$ of the fixed cost $f$. In an imperfect credit market, this need for credit implies additional costs of external finance. We follow Rajan and Zingales (1998) in that the need for outside capital arises from technological reasons and is thus the same for all firms in the differentiated good industry. Following Manova (2010), we assume imperfect contract enforcement. Creditors are repaid with probability $\lambda, \lambda \in[0,1)$. Hence, with probability $(1-\lambda)$ a firm defaults. Creditors thus require a collateral that they can seize in case of default. We assume that a fraction $\delta, \delta \in(0,1)$ of the capital and equipment required to start production (as captured by the market entry costs $\left.f_{E}\right)$ serves as collateral. Creditors recover only a fraction $\theta, \theta \in(0,1)$ of the collateral as they incur liquidation costs (e.g. Schnitzer et al., 2009), e.g. because the collateral good cannot be sold at the original price. Another reason might be that creditors might need to invest time and effort in order to sell the collateral good because they do not have sufficient knowledge of the industry. Creditors make firms a take-it-or-leave offer specifying the required amount of repayment $R$. The credit market is perfectly competitive,

\footnotetext{
${ }^{4}$ Note that for cost draws $c \in[0, t)$, this specification implies negative labor input. This can be ruled out by restricting cost draws to $c \geq t$. An alternative, but formally equivalent, interpretation of $t$ is an increase in the price margin through product innovation or the adoption of an advanced technology that increases quality at unchanged cost. This interpretation does not require a restriction of cost draws and hence will be alluded to in order to avoid limiting the cost distribution.

${ }^{5}$ Modelling a continuous investment decision, e.g. $\max \pi=t^{\phi}(p-c) q-t$, instead of a binary one makes the analysis cumbersome but leaves the results qualitatively unchanged: "opening up" reduces investment of purely domestic firms and has a positive larger market and a negative import competition effect on the investment of exporters.
} 
that is creditors break even in expected terms. The zero profit condition for creditors for a credit of size $d f$ is given by

$$
\lambda R+(1-\lambda) \theta \delta f_{E} \geq d f
$$

implying a repayment of

$$
R=\frac{d}{\lambda} f-\frac{(1-\lambda) \theta}{\lambda} \delta f_{E} \cdot{ }^{6}
$$

Without advanced technology adoption, the total cost of production is given by

$$
T C(c)=c q(c)
$$

The total cost function of firms using the advanced technology, $T C_{A}$, depends on the level of credit market frictions:

$$
T C_{A}(c)=(c-t) q_{A}(c)+(1-d) f+\lambda R+(1-\lambda) \delta f_{E}=(c-t) q_{A}(c)+f+f_{\mathrm{ext}},
$$

where $f_{\text {ext }}=(1-\lambda)(1-\theta) \delta f_{E}$. Lower contract enforcement, higher liquidation costs and fewer tangible assets increase the costs of external finance and thereby the total costs of technology adoption.

Exporting. Trade between countries involves trade costs that consist of a fixed (market entry costs) and a variable component (transport costs, tariffs). Following Ottaviano et al. (2009), we collapse all trade costs into a single indicator. The traditional formulation of iceberg transport costs implies that more productive firms (those with lower cost draws) have access to a lower cost transport technology. As a consequence, reallocation forces are distorted (Schroeder and Sorensen, 2011; Irarrazabal et al., 2011). Therefore, we assume per-unit trade costs, $\tau>0$.

\subsection{Firm behavior}

Prices and profits. Let $p_{D}, p_{X}, p_{D A}, p_{X A}$ denote the price in the domestic and in the export market of firms using the baseline technology and of firms using the advanced technology,

\footnotetext{
${ }^{6}$ We assume that $f \geq(1-\lambda) \theta \delta f_{E} / d$ such that $R \geq 0$.
} 
respectively. Profit maximization implies:

$$
\begin{aligned}
p_{D} & =\frac{1}{2}\left(p_{\max }+c\right), \quad p_{X}=\frac{1}{2}\left(p_{\max }^{*}+c+\tau\right) \\
p_{D A} & =\frac{1}{2}\left(p_{\max }+c-t\right), \quad p_{X A}=\frac{1}{2}\left(p_{\max }^{*}+c+\tau-t\right) .
\end{aligned}
$$

Prices charged by firms using the advanced technology are lower, $p_{D A}=p_{D}-t / 2$ and $p_{X A}=p_{X}-t / 2$. Accordingly, quantities sold are higher. Technology adoption increases thus variable profits but involves fixed cost. The profits of firms serving only the domestic market using the baseline and the advanced technology are given by:

$$
\pi_{D}=\frac{S}{4 \gamma}\left(p_{\max }-c\right)^{2}, \quad \pi_{D A}=\frac{S}{4 \gamma}\left(p_{\max }-c+t\right)^{2}-f-f_{\mathrm{ext}}
$$

Profits of firms serving also the foreign market are respectively

$$
\begin{aligned}
\pi & =\pi_{D}+\pi_{X}=\frac{S}{4 \gamma}\left[\left(p^{\max }-c\right)^{2}+\left(p_{\max }^{*}-c-\tau\right)^{2}\right] \\
\pi_{A} & =\pi_{D A}+\pi_{X A}=\frac{S}{4 \gamma}\left[\left(p^{\max }-c+t\right)^{2}+\left(p_{\max }^{*}-c-\tau+t\right)^{2}\right]-f-f^{\text {ext }} .
\end{aligned}
$$

Firms' sorting pattern. Denote with $c_{D}, c_{X}$, and $c_{A}$ the cost cutoffs below which firms stay in the market and produce, serve the foreign market, and invest in technology adoption. A number of empirical studies shows that only a subset of domestic producers serves the foreign market and/or uses an advanced production technology, that is $c_{X}<c_{D}$ and $c_{A}<c_{D}$ (e.g. Bernard and Jensen, 1999). Furthermore, there are two possible sorting patterns (Figure 1). In the first case $\left(c_{A}<c_{X}\right)$, serving only the domestic market and using an advanced

Figure 1: Plausible sorting patterns

\begin{tabular}{|llllll}
\hline advanced, exporter & $c_{A}$ & baseline, exporter & $c_{X}$ & baseline, domestic $c_{D}$ \\
& & & & \\
\hline advanced, exporter & $c_{X}$ & advanced, domestic & $c_{A}$ & baseline, domestic $\quad c_{D}$
\end{tabular}

technology is always dominated by some other choice. This case obtains if the fixed cost of technology adoption $f$ is high. In the opposite case $\left(c_{X}<c_{A}\right)$, the marginal technology adopter is a purely domestic firm, that is all exporters use the advanced technology (low 
$f)$. The technology adoption decision is then only indirectly affected by trade liberalization whereas in the first case, opening up to trade affects this decision directly. Given the aim of the paper, we therefore focus on the first case and assume that $c_{A}<c_{X}<c_{D}$. The necessary parameter restrictions are provided below. ${ }^{7}$ Thus, there are four types of firms. Firms with a cost draw above $c_{D}$ immediately exit the market. Firms with marginal cost between $c_{D}$ and $c_{X}$ are purely domestic producers and those with costs between $c_{X}$ and $c_{A}$ also serve the foreign market. The most productive firms with production cost below $c_{A}$ adopt the advanced technology and serve the foreign market.

Firm decisions. The least productive firms serve only the domestic market and use the baseline technology. They decide to stay in the market and produce if their profits $\pi_{D}$ are non-negative:

$$
\pi_{D}\left(c_{D}\right)=0 \Leftrightarrow c_{D}=p_{\max }
$$

A lower entry cutoff $c_{D}$ reflects tougher selection and a more competitive market. Using (11), profits described in (9) and (10) can be rewritten as

$$
\begin{aligned}
\pi_{D} & =\frac{S}{4 \gamma}\left(c_{D}-c\right)^{2} \\
\pi & =\pi_{D}+\pi_{X}=\frac{S}{4 \gamma}\left[\left(c_{D}-c\right)^{2}+\left(c_{D}^{*}-c-\tau\right)^{2}\right] \\
\pi_{A} & =\pi_{D A}+\pi_{X A}=\frac{S}{4 \gamma}\left[\left(c_{D}-c+t\right)^{2}+\left(c_{D}^{*}-c-\tau+t\right)^{2}\right]-f-f_{\mathrm{ext}} .
\end{aligned}
$$

Firms export if they can profitably serve the foreign market. This is the case if their production cost is below the export cutoff $c_{X}$ where

$$
\pi_{X}\left(c_{X}\right)=0 \Leftrightarrow c_{X}=c_{D}^{*}-\tau
$$

Exporters invest in technology adoption if their total profits are higher when using the advanced technology, that is if $\pi_{A}(c) \geq \pi(c)$. Technology adoption increases variable profits but involves fixed costs. This trade-off is depicted in Figure 2. Firms with cost draws below the technology adoption cutoff $c_{A}$ invest in technology adoption. Their scale of production is very large so that it pays for them to bear the investment cost $f+f_{\text {ext }}$ :

$$
\pi_{A}\left(c_{A}\right)=\pi\left(c_{A}\right) \Leftrightarrow c_{A}=\frac{1}{2}\left(c_{D}+c_{D}^{*}+t-\tau-\frac{2 \gamma}{S t} \psi f\right)
$$

\footnotetext{
${ }^{7}$ Bustos (2011) and Lederman et al. (2005) provide empirical support for this assumption on firms' sorting pattern.
} 


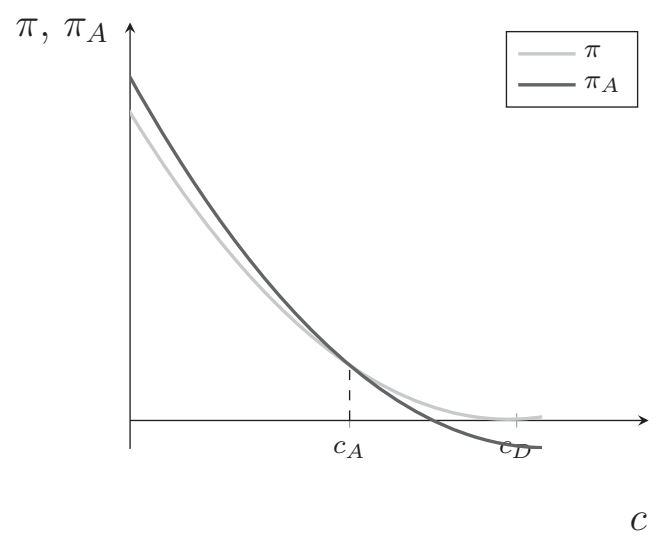

Figure 2: Technology adoption trade-off

where $\psi=1+\frac{(1-\lambda)(1-\theta) \delta f_{E}}{f}$. Using (11), (13), and (14), we can now state a condition for our assumption on firms' sorting pattern:

$$
f_{\min } \equiv\left(c_{D}-c_{X}+t\right) \frac{S t}{2 \gamma \psi}<f<\left(c_{D}+c_{X}+t\right) \frac{S t}{2 \gamma \psi} \equiv f_{\max }
$$

where $f_{\min }$ and $f_{\max }$ describe the range of $f$ as a function of $\psi$ for which $0<c_{A}<c_{X}<c_{D}{ }^{8}$ Credit market frictions - imperfect contract enforcement, liquidation costs, lack of tangible assets - decrease access to external finance and thereby increase the total costs of investment. Hence, firms in a less developed credit market need to be more productive in order to have an incentive to invest in technology adoption. This is reflected by a higher technology adoption cutoff: $d c_{A} / d \psi<0$. It follows that firms with cost draws $c \in\left[\left(c_{A}, c_{A}(\psi=1)\right)\right.$ would invest in technology adoption in a perfect credit market but are prevented from doing so by $f_{\text {ext }}>0$. These are the missing high-technology firms.

\subsection{Pareto distributed production cost}

We assume that productivity (as implied by the cost draw) $1 / c$ is Pareto distributed with lower bound $1 / c_{M}$ and shape parameter $k \geq 1$. It follows that marginal cost $c$ is also Pareto distributed with shape parameter $k \geq 1$ and support $\left[0, c_{M}\right]$ :

$$
G(c)=\left(\frac{c}{c_{M}}\right)^{k}, \quad c \in\left[0, c_{M}\right] .
$$

\footnotetext{
${ }^{8}$ Note that both $c_{D}$ and $c_{D}^{*}$ depend on $\tau, k, t, f, \gamma, \psi, S, f_{E}, c_{M}$.
} 
The Pareto distribution has been intensively used in the recent literature as several studies have suggested that it matches the firm size distribution (e.g. Axtell, 2001; Del Gatto et al., 2006; Helpman et al., 2004). Furthermore, it makes the analysis highly tractable and easily lends itself to interpretation. The upper bound on marginal cost $c_{M}$ indicates how cost effective the economy is in producing the differentiated good. A higher $c_{M}$ implies higher average cost of production. The shape parameter $k$ governs the dispersion of the cost distribution. If $k=1, G(c)$ corresponds to the uniform distribution. A higher $k$ implies a higher cost concentration and thus higher average cost of production. Moreover, any truncation of the Pareto distribution is also a Pareto distribution with shape paramater $k$. The ex-ante distribution of successful entrants is the Pareto distribution in (16) truncated at the entry cutoff $c_{D}$

$$
G_{c_{D}}(c)\left(\frac{c}{c_{D}}\right)^{k}, \quad c \in\left[0, c_{D}\right] .
$$

From the law of large numbers (LLN), this is also the ex-post distribution of domestic producers. The ex-ante probability of using the baseline and the advanced technology, conditional on being a producer, is given by $\left[G\left(c_{D}\right)-G\left(c_{A}\right)\right] / G\left(c_{D}\right)$ and $G\left(c_{A}\right) / G\left(c_{D}\right)$ respectively. By the LLN, these expressions also represent the fraction of low-technology and high-technology firms among domestic producers, $N_{D L} / N_{D}$ and $N_{D A} / N_{D}$, where $N_{D}, N_{D L}$ and $N_{D A}$ denote the absolute number of domestic producers and of domestic low-technology and high-technology firms.

The average cost of production $(\overline{C o P})$ of domestic firms is then given by

$$
\begin{aligned}
\overline{C o P} & =\frac{N_{D A}}{N_{D}} \int_{0}^{c_{A}}(c-t) \frac{g(c)}{G\left(c_{A}\right)} d c+\frac{N_{D L}}{N_{D}} \int_{c_{A}}^{c_{D}} c \frac{g(c)}{G\left(c_{D}\right)-G\left(c_{A}\right)} d c \\
& =\frac{k}{k+1} c_{D}-t\left(\frac{c_{A}}{c_{D}}\right)^{k} .
\end{aligned}
$$

In the following, we focus on the average cost of production as our (inverse) measure of average productivity. As an alternative measure, we also consider aggregate cost where $c$ is weighted either by demand $q(c)$ or by revenues $r(c)$ as (inverse) measure of aggregate productivity (see Proof of Proposition 1 in Appendix for analytical expressions of aggregate cost).

\section{Equilibrium Analysis}

There is an unbounded mass of ex-ante identical firms who decide whether or not to enter the differentiated good industry. Free entry into the industry ensures that ex-ante expected 
profits are zero in equilibrium: firms enter until ex-post expected profits correspond to the fixed entry costs. The free entry condition is

$$
f_{E}=\int_{0}^{c_{A}} \pi_{A}(c) d F(c)+\int_{c_{A}}^{c_{X}} \pi(c) d F(c)+\int_{c_{X}}^{c_{D}} \pi_{D}(c) d F(c) .
$$

And, solving the integral,

$$
\frac{\left(c_{D}\right)^{k+2}+\left(c_{D}^{*}-\tau\right)^{k+2}}{k+2}+2 t\left(c_{A}\right)^{k+1}=\frac{f_{E} 2 \gamma\left(c_{M}\right)^{k}(k+1)}{S},
$$

where $c_{A}$ is given by (14). The free entry condition for the foreign country is analogous. Each free entry condition will hold as long as there is a positive mass of domestic entrants $N_{E}>0$ $\left(N_{E}^{*}>0\right)$. Otherwise, the respective country abandons the production of the differentiated good and specializes in the numéraire. ${ }^{9}$

(19) describes a system of two equations with two unknowns $\left(c_{D}\right.$ and $\left.c_{D}^{*}\right)$. An equilibrium in which both countries produce the differentiated good exists if and only if the solution of (19), $\left(c_{D}, c_{D}^{*}\right)$, takes positive and real values. Lemma 1 shows the conditions under which this is the case. $c_{D}$ and $c_{D}^{*}$ cannot explicitly be solved for because (i) they enter $c_{A}$ and $c_{A}^{*}$ additively and (ii) $c_{A}$ and $c_{A}^{*}$ enter in a nonlinear way. However, it is possible to show that there is a unique equilibrium.

Lemma 1. Provided that $\psi$, for a given $\psi^{*}$, is not too large and thus the difference in credit market development between home and foreign country is not too large, there is a unique equilibrium pair of $c_{D}$ and $c_{D}^{*}$.

Proof. See Mathematical Appendix.

This is illustrated in Figures 3 and 4: $\mathrm{FE}$ and $\mathrm{FE}^{*}$ plot the free entry conditions of the home and the foreign country in the $\left(c_{D}, c_{D}^{*}\right)$ space. Figure 3 depicts the symmetric equilibrium $\left(\psi=\psi^{*}\right)$. In the symmetric case, the two countries share the same entry cutoff, $c_{D}=c_{D}^{*}=c_{D}^{\mathrm{symm}}$.

In the following, we assume that the home country has a less developed credit market. Figure 4 shows the asymmetric equilibrium $\left(\psi>\psi^{*}\right)$ : higher costs of external finance cause

\footnotetext{
${ }^{9} N_{E}=\left\{\left(c_{M}\right)^{k} /\left[\left(c_{D}\right)^{k}\left(c_{D}^{*}\right)^{k}-\left(c_{X}\right)^{k}\left(c_{X}^{*}\right)\right]\right\}\left[N\left(c_{D}^{*}\right)^{k}-N^{*}\left(c_{X}^{*}\right)^{k}\right] \leq 0$ implies $N_{E}^{*}=$ $\left\{\left(c_{M}\right)^{k} /\left[\left(c_{D}\right)^{k}\left(c_{D}^{*}\right)^{k}-\left(c_{X}\right)^{k}\left(c_{X}^{*}\right)\right]\right\}\left[N^{*}\left(c_{D}\right)^{k}-N\left(c_{X}\right)^{k}\right]>0$. Hence, at most one country specializes in the numéraire. In the following analysis, we assume that $N_{E}>0$ and $N_{E}^{*}>0$.
} 


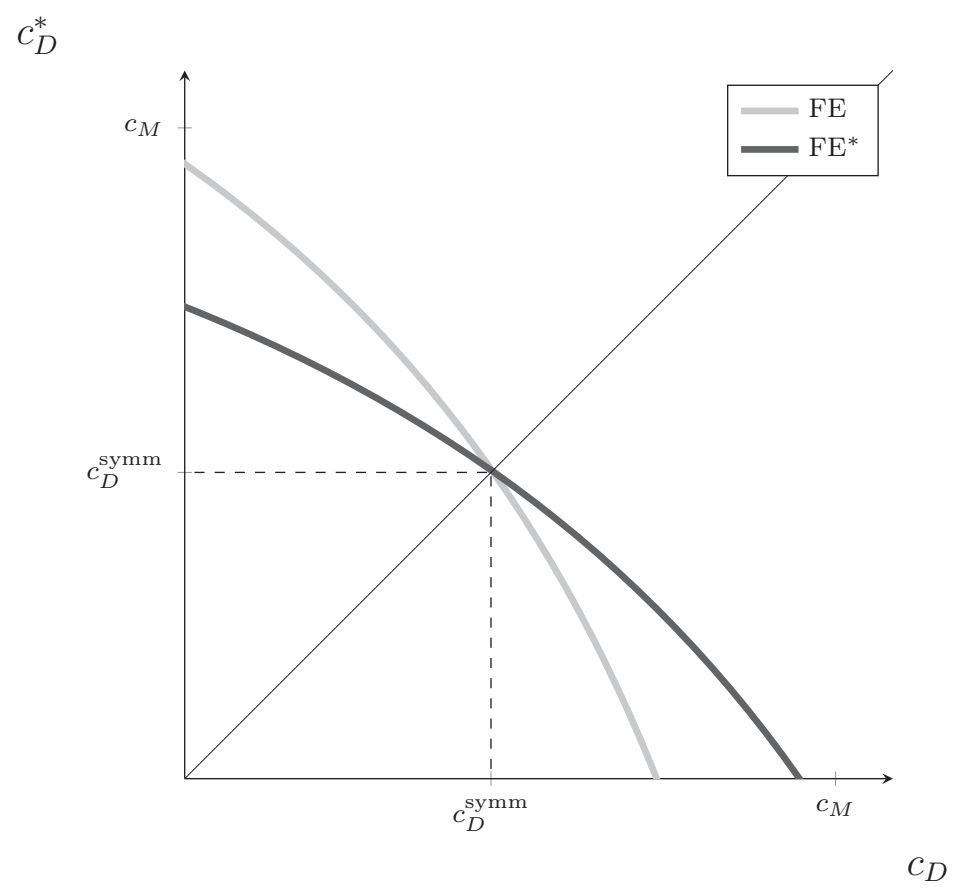

Figure 3: Open economy equilibrium: Symmetric countries $c_{D}^{*}$

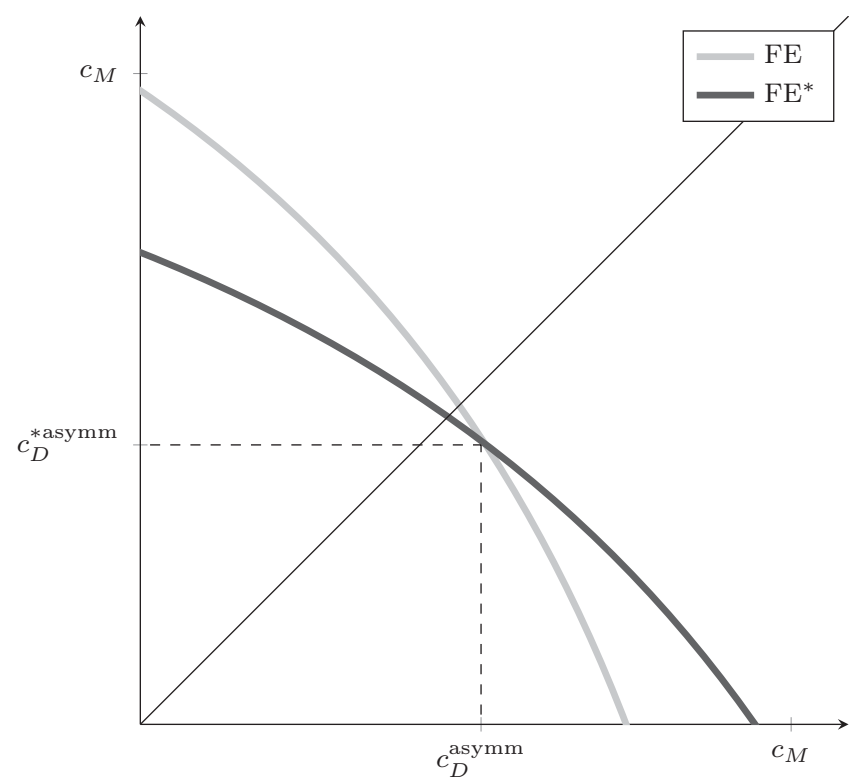

$c_{D}$

Figure 4: Open economy equilibrium: Asymmetric countries 
an outward shift of the home country's free entry condition curve. Compared to the symmetric case, the resulting equilibrium entry cutoff is lower in the foreign country and higher in the home country, that is $c_{D}^{\text {*asymm }}<c_{D}^{\text {symm }}<c_{D}^{\text {asymm }}$. Formally, this is reflected by the free entry conditions described by (19). Higher costs of external finance make technology upgrading in the home country more expensive than in the foreign country. Some exporters who use the advanced technology in the symmetric case now abstain from technology upgrading. Therefore, ex-ante expected profits and firm entry are lower as reflected by a higher entry cutoff. A higher entry cutoff implies softer selection: average productivity, that is average competitiveness, is lower. The contrary holds for the foreign country.

$c_{D}>c_{D}^{*}$ implies, by (13), that the export cutoff is lower in the home country. Furthermore, the fraction of exporters, given by $\left(c_{X} / c_{D}\right)^{k}$, is lower. From (14) it follows that the technology adoption cutoff and therefore the fraction of high-technology firms, given by $\left(c_{A} / c_{D}\right)^{k}$, is also lower in the home country.

The following proposition summarizes this discussion.

Proposition 1. Suppose that $f_{\min }<f<f_{\max }$ such that in equilibrium the following order of cutoffs holds: $0<c_{A}<c_{X}<c_{D}$. Suppose further that $\psi>\psi^{*}$. The fraction of exporters, the fraction of high-technology firms and the average productivity of domestic firms are higher in the foreign country. Furthermore, the larger the difference in credit market development $\left(\psi / \psi^{*}\right.$ increases $)$, the larger the absolute and relative difference between the two countries, that is:

$$
\begin{aligned}
& \text { - } \frac{d\left[\left(\frac{c_{X}^{*}}{c_{D}^{*}}\right)^{k}-\left(\frac{c_{X}}{c_{D}}\right)^{k}\right]}{d \psi}>0, \frac{d\left[\left(\frac{c_{A}^{*}}{c_{D}^{*}}\right)^{k}-\left(\frac{c_{A}}{c_{D}}\right)^{k}\right]}{d \psi}>0, \frac{d\left(\overline{C o P}-\overline{C o P^{*}}\right)}{d \psi}>0 \\
& \text { - } \frac{d\left[\left(\frac{c_{X}^{*}}{c_{D}^{*}}\right)^{k} /\left(\frac{c_{X}}{c_{D}}\right)^{k}\right]}{d \psi}>0, \frac{d\left[\left(\frac{c_{A}^{*}}{c_{D}^{*}}\right)^{k} /\left(\frac{c_{A}}{c_{D}}\right)^{k}\right]}{d \psi}>0, \frac{d\left(\overline{C o P} / \overline{C o P^{*}}\right)}{d \psi}>0 .
\end{aligned}
$$

Proof. See Mathematical Appendix.

\section{Trade liberalization}

In the following, we study the effects of trade liberalization via a decrease in trade barriers $\tau .{ }^{10}$ As a benchmark case, we start by analyzing the symmetric case.

\footnotetext{
${ }^{10}$ This paper develops a static model. Trade liberalization is thus the comparative statics analysis of how a situation with high trade barriers compares to a situation with lower trade barriers. However, as in Melitz and Ottaviano (2008), the different situations can be interpreted as steady state equilibria.
} 


\subsection{Benchmark: Symmetric countries}

The impact of trade liberalization on the symmetric equilibrium is depicted in Figure 5. $c_{D}, c_{D}^{*}$ is the equilibrium before trade liberalization and $c_{D}^{\prime}, c_{D}^{*^{\prime}}$ the equilibrium after trade liberalization. A reduction in trade costs $\tau$ causes an inward shift of the free entry condition curves. For a given entry cutoff in the foreign country, the entry cutoff in the home country is now lower. The intersection of the two curves moves along the 45-degree line towards the origin. Hence, in the new equilibrium, both entry cutoffs are lower. In the symmetric case,

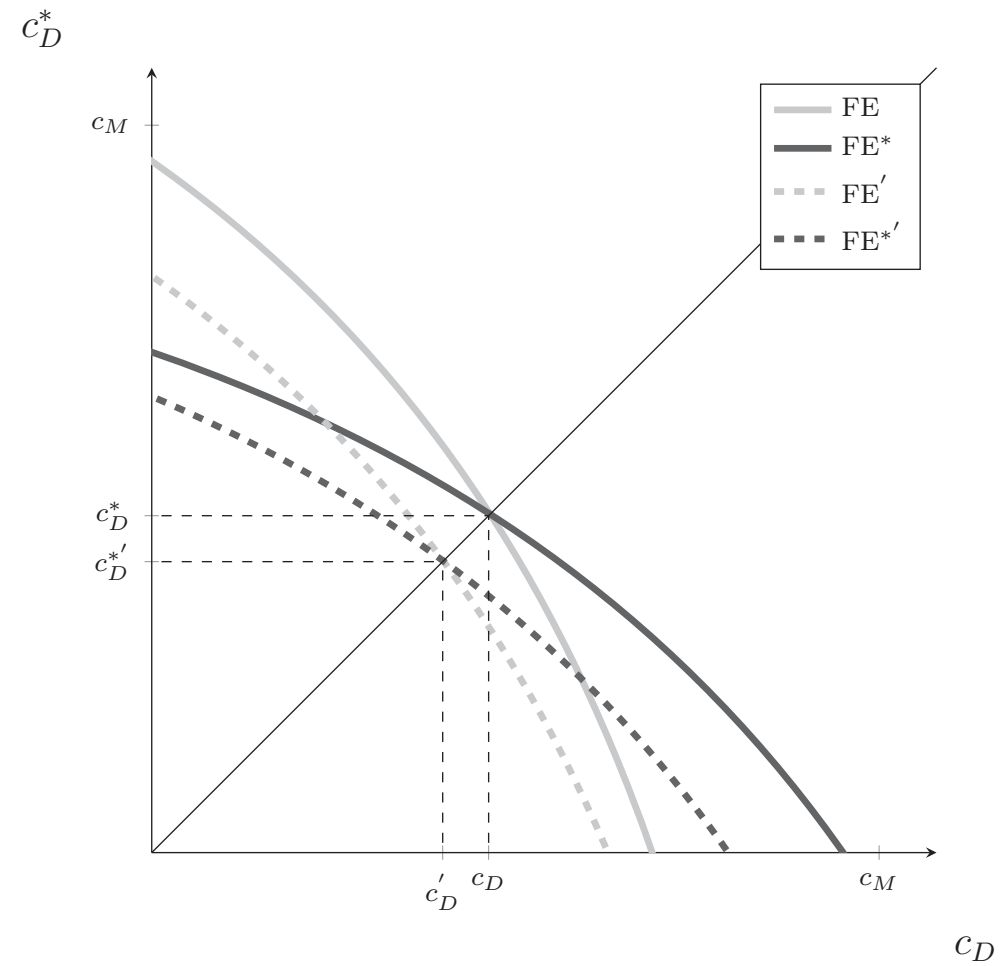

Figure 5: Trade liberalization: Symmetric countries

the free entry condition (19) reduces to

$$
\frac{\left(c_{D}\right)^{k+2}+\left(c_{D}-\tau\right)^{k+2}}{k+2}+2 t\left(c_{A}\right)^{k+1}=\frac{f_{E} 2 \gamma c_{M}^{k}(k+1)}{S} .
$$

From (20) we can derive that lower trade barriers $\tau$ imply higher expected profits and therefore more entries and a lower entry cutoff (see Proof of Proposition 2 in Appendix):

$$
\frac{d c_{D}}{d \tau}>0
$$


A reduction in trade costs lowers the delivered costs abroad and increases the foreign demand for imports. Exporters thus serve a larger market abroad and realize higher profits. However, import competition at home increases also, since lower trade costs increase the competitiveness of foreign exporters. The least productive domestic producers start making losses and exit the market. This is the well-known selection effect pointed out by Melitz (2003): trade liberalization reallocates production to the most productive firms.

Differentiating the export cost cutoff (13) with respect to trade barriers $\tau$, we obtain

$$
\frac{d c_{X}}{d \tau}=\frac{d c_{D}}{d \tau}-1<0
$$

Trade liberalization has two opposing effects on the export cost cutoff given by the first and second term in (22). Lower trade barriers allow the most productive domestic firms to start exporting (second term). On the other hand, trade liberalization increases competition abroad and makes it more difficult to profitably export (first term). It can be shown that the first effect dominates (see Proof of Proposition 2 in Appendix). Hence, as in standard heterogenous-firm trade models, the export cutoff and the fraction of exporters, $\left(c_{X} / c_{D}\right)^{k}$, increase after trade liberalization.

The novelty here is that we can also analyze the effect on the incentive to upgrade technology. From the expression for the technology adoption cutoff (14), the impact of trade liberalization on technology upgrading is given by

$$
\frac{d c_{A}}{d \tau}=\frac{1}{2}\left(2 \frac{d c_{D}}{d \tau}-1\right)<0
$$

A reduction in trade barriers increases the market abroad and induces the most productive low-technology firms to upgrade their technology. This larger market or pro technologyadoption effect is reflected by the second term in the brackets. Trade liberalization increases import competition and reduces market shares at home. The first term represents this anti technology-adoption effect. The net effect of lower trade barriers on the technology adoption cutoff is pro technology-adoption: total output of the most productive low-technology firms increases. Therefore, these firms have a higher return to technology upgrading. Hence, they now invest in the advanced technology. This is expressed by an increase in the technology adoption cutoff $c_{A}$. The fraction of high-technology firms, $\left(c_{A} / c_{D}\right)^{k}$, increases as well.

Proposition 2. Suppose that $f_{\min }<f<f_{\max }$ such that in equilibrium the following order of cutoffs holds: $0<c_{A}<c_{X}<c_{D}$. Suppose further that countries are identical. $A$ reduction in trade costs $\tau$ increases the fraction of exporters, the fraction of high-technology 
firms, and average productivity. ${ }^{11}$

Proof. See Mathematical Appendix.

\subsection{Asymmetric countries}

How do the results above change if the home country has a less developed credit market and therefore higher costs of external finance? The intuition is best explained graphically (see Proof of Proposition 3 in Appendix for analytical derivations). Figure 6 depicts the new equilibrium.

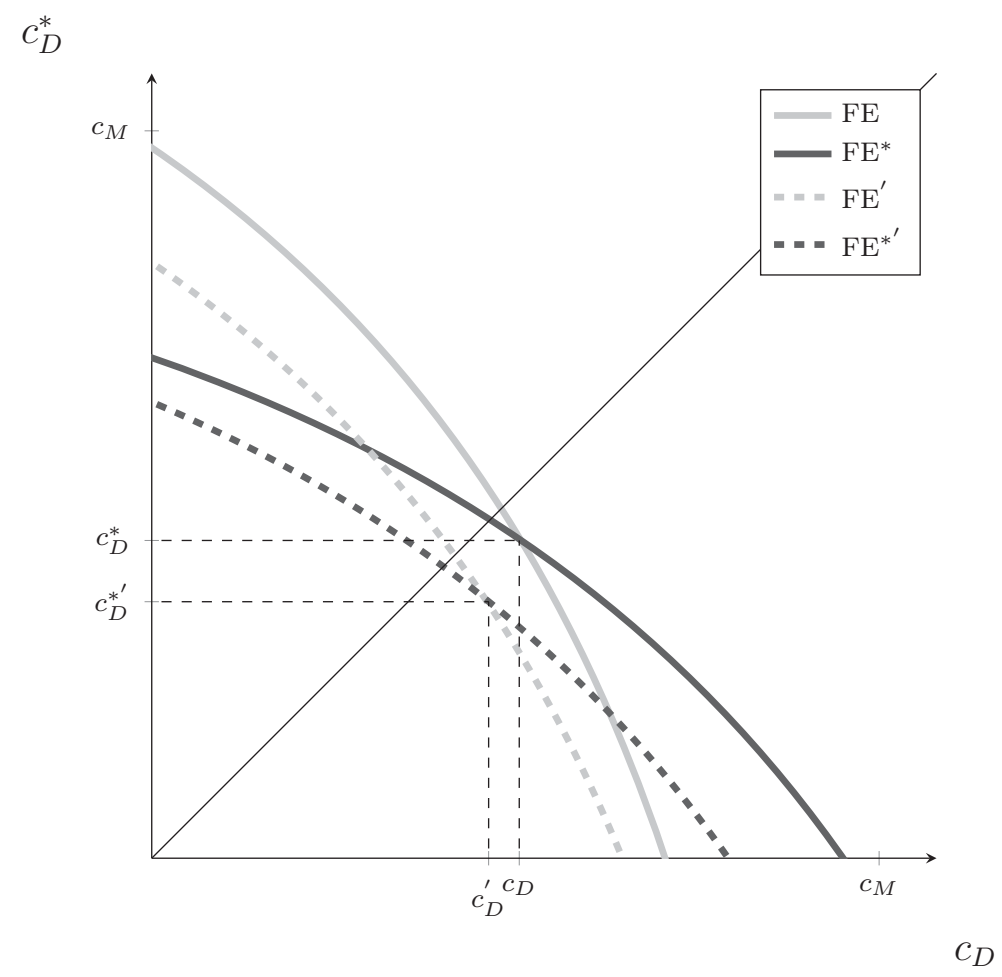

Figure 6: Trade liberalization: Asymmetric countries

A reduction in trade barriers still causes an inward shift of both free entry condition curves. However, in contrast to the symmetric case, the entry cutoff in the home country decreases less. The decrease in the entry cutoff in the foreign country, on the other hand, is stronger and the more so the more severe the credit constraints in the home country are.

\footnotetext{
${ }^{11}$ If $0<c_{X}<c_{A}<c_{D}$, the marginal technology adopter is a purely domestic firm. As trade liberalization reduces domestic production, only the anti-technology adoption effect is at work and the technology adoption cutoff unambiguously decreases.
} 
Hence, $d c_{D} / d \tau<d c_{D}^{*} / d \tau$. The reason for this is, as will be shown in the following, that the (initial) export and technology adoption cutoff are higher in the foreign country. Put differently, the (initial) fraction of exporters and high-technology firms is higher and more firms can take advantage of the larger export market after trade liberalization. Therefore, ex-ante expected profits and entry increase more in the foreign country implying a stronger selection effect.

The effect of trade liberalization on the export cost cutoff is given by

$$
\frac{d c_{X}}{d \tau}=\frac{d c_{D}^{*}}{d \tau}-1<0, \frac{d c_{X}^{*}}{d \tau}=\frac{d c_{D}}{d \tau}-1<0
$$

Hence, the export cutoff and the fraction of exporters increase in both countries if $\tau$ decreases. Moreover, it can be shown that the difference between the two countries with respect to the fraction of exporters increases as $\tau$ decreases:

$$
\frac{d\left[\left(\frac{c_{X}^{*}}{c_{D}^{*}}\right)^{k}-\left(\frac{c_{X}}{c_{D}}\right)^{k}\right]}{d \tau}<0
$$

The effect of trade liberalization on the technology adoption cutoff (and hence, on the fraction of high-technology firms) is positive:

$$
\frac{d c_{A}}{d \tau}=\frac{d c_{A}^{*}}{d \tau}=\frac{1}{2}\left(\frac{d c_{D}}{d \tau}+\frac{d c_{D}^{*}}{d \tau}-1\right)<0
$$

The first term in the brackets describes again the import competition or anti technologyadoption effect and the second term the larger market or pro technology-adoption effect. The anti technology-adoption effect reflects the increase in competition in the home and in the foreign market after trade liberalization. Since high-technology firms belonging to either country are active in both markets, it is the same for both countries. It decreases in the entry cutoffs $c_{D}$ and $c_{D}^{*}$, that is the strength of this effect depends on the initial (before trade liberalization) level of these cutoffs: for a given increase in ex-post expected profits, the entry cutoff $c_{D}$ has to decrease the more, the lower it was initially, in order to satisfy the free entry condition. The pro technology-adoption effect is also the same for both countries. ${ }^{12}$ Hence, the marginal increase in the technology adoption cutoff after trade liberalization is identical across countries and the difference in the technology adoption cutoffs $c_{A}$ and $c_{A}^{*}$ is unchanged, $d\left(c_{A}^{*}-c_{A}\right) / d \tau=0$. This implies that the percentage increase, $\left(d c_{A} / d \tau\right) / c_{A}$, is higher in the home country.

\footnotetext{
${ }^{12}$ This is due to the per-unit specification of trade costs ( $\tau$ enters $c_{A}$ additively).
} 
We are interested in particular in the impact on the fraction of high-technology firms, $\left(c_{A} / c_{D}\right)^{k}$ and $\left(c_{A}^{*} / c_{D}^{*}\right)^{k}$, as an indicator of the average technology level of home and foreign country. The increase in the technology adoption cutoff is the same in both countries. The selection effect, however, is larger in the foreign country, that is $c_{D}^{*}$ decreases more than $c_{D}$. Therefore, the difference in the fraction of firms that use the advanced technology increases as $\tau$ decreases:

$$
\frac{d\left[\left(\frac{c_{A}^{*}}{c_{D}^{*}}\right)^{k}-\left(\frac{c_{A}}{c_{D}}\right)^{k}\right]}{d \tau}<0 .
$$

From (18), average cost of production (our main (inverse) measure of productivity) in home and foreign country is given by

$$
\frac{k}{k+1} c_{D}-t\left(\frac{c_{A}}{c_{D}}\right)^{k}, \frac{k}{k+1} c_{D}^{*}-t\left(\frac{c_{A}^{*}}{c_{D}^{*}}\right)^{k} .
$$

A stronger selection effect in the foreign country implies a larger decrease in the average cost draw, that is in average production cost of low-technology firms (first term). Moreover, from (26), the difference between the two countries in terms of the fraction of high-technology firms is even larger after trade liberalization (second term). Hence, average productivity increases more in the foreign country: trade liberalization widens the average productivity gap. This is summarized in the following Proposition:

Proposition 3. Suppose that $f_{\min }<f<f_{\max }$ such that in equilibrium the following order of cutoffs holds: $0<c_{A}<c_{X}<c_{D}$. Suppose further that $\psi>\psi^{*}$. A reduction in trade costs $\tau$ increases the fraction of exporters, the fraction of high-technology firms, and average productivity in both countries. However, the absolute difference between the two countries with respect to the fraction of exporters, the fraction of high-technology firms, and average productivity increases as well. Furthermore, the relative average productivity increases:

$$
\begin{aligned}
& \text { - } \frac{d\left[\left(\frac{c_{X}^{*}}{c_{D}^{*}}\right)^{k}-\left(\frac{c_{X}}{c_{D}}\right)^{k}\right]}{d \tau}<0, \frac{d\left[\left(\frac{c_{A}^{*}}{c_{D}^{*}}\right)^{k}-\left(\frac{c_{A}}{c_{D}}\right)^{k}\right]}{d \tau}<0, \frac{d\left(\overline{C o P}-\overline{C o P^{*}}\right)}{d \tau}<0 \\
& \text { - } \frac{d\left(\overline{C o P} / \overline{C o P^{*}}\right)}{d \tau}<0 .
\end{aligned}
$$

Proof. See Mathematical Appendix.

The impact of a reduction in $\tau$ on the relative difference between the two countries with respect to the fraction of exporters and the fraction of high-technology firms cannot be determined analytically. For our parametrization introduced in section 5, we can show that 
the relative difference increases after trade liberalization (see Table 6 in the Appendix). In addition, we consider a measure of aggregate productivity which corresponds to the cost of production weighted either by demand $q(\mathrm{c})$ or by revenues $\mathrm{r}(\mathrm{c})$. The impact of trade liberalization on the aggregate productivity gap can be analyzed only numerically. We do this in section 5 .

Thus, trade liberalization increases economic performance, average productivity and the adoption of advanced technologies, in both countries. However, a reduction in trade costs without improved access to credit - is not enough to ensure convergence between home and foreign country. Credit market deficiencies prevent the home country to take full advantage of the opportunities offered by trade liberalization. First, as fewer firms can take advantage of the larger export market, the selection effect is less severe. Hence, efficiency gains through resource allocation from less to more productive firms are lower. Second, while a reduction in trade costs increases the adoption of advanced technologies, the gap with respect to the fraction of high-technology firms, does not close. For both reasons, relative average productivity of the country with a developed credit market increases.

\section{$5 \quad$ Welfare analysis}

In the following, we parametrize the model to conduct a welfare analysis.

\subsection{Parametrization}

The parameters representing trade costs $(\tau)$, industry cost effectiveness $(k)$, technological leap $(t)$ and product differentiation $(\gamma)$ are taken from empirical studies and calibrations to connect the model to real data. We allow $\tau \in[0.7,1]$ as this reduction of $30 \%$ corresponds to the typical reduction in trade costs in the industries most affected by trade liberalization (Constantini and Melitz, 2008). Del Gatto et al. (2006) estimate $k=2$ across 18 industries in 11 Western European countries. In line with Bernard et al. (2003), Behrens et al. (2007) calibrate $k=3.6$. We set $k=2.5$. The technological leap $t$ is set to 0.5 which corresponds to $10 \%$ of the average cost of production in our basic specification below. This is in line with Constantini and Melitz (2008), who calibrate a model of trade liberalization and technology adoption. Finally, Ottaviano et al. (2009) estimate the degree of product differentiation in 12 industries using data on $12 \mathrm{EU}$ countries for the years 2001-2003. Calculating the average across all industries, we use $\gamma=0.2$.

Entry costs $\left(f_{E}\right)$, the upper bound on marginal cost $\left(c_{M}\right)$, and market size $(S)$, are scale parameters that are chosen to be in line with our assumption about the cutoff ranking, 
namely

$$
0<c_{A}<c_{X}<c_{D}<c_{M}
$$

The range of parameter values to measure credit market development $\left(\psi, \psi^{*}\right)$ is selected to satisfy $(27), q_{0}^{c}>0, N_{E}>0$ and $N_{E}^{*}>0$ and to allow for a large enough difference in the total technology adoption costs between the two countries. In particular, $S=1, f_{E}=10=c_{M}$, $\psi, \psi^{*} \in[1,1.25]$. Furthermore, the fixed cost of technology adoption is set to $f=10$.

Our preferred specification ("basic specification") is given by

- $\tau=0.8$

- $k=2.5$

- $t=0.5$

- $\gamma=0.2$.

\subsection{Welfare analysis}

We use the indirect utility function associated with (1) to analyze the implications for social welfare (see Melitz and Ottaviano (2008), p. 298):

$$
W=I^{c}+\frac{N}{\gamma} \frac{\sigma_{p}^{2}}{2}+\frac{1}{2}\left(\frac{\gamma}{N}+\beta\right)^{-1}(\alpha-\bar{p})^{2}
$$

Welfare increases with an increase in the number of varieties sold in the market $(N)$ and in the price variance $\left(\sigma_{p}^{2}\right)$, and decreases with an increase in the average price $(\bar{p})$.

The average price in the open economy is

$$
\bar{p}=\frac{2 k+1}{2(k+1)} c_{D}-\left(p-p^{A}\right) \frac{N_{A}}{N}+\frac{\left(p^{X}-p\right)}{k+1} \frac{N_{X}^{*}}{N},
$$

where the first term gives the average price of low-technology firms and the second term the price difference between low- and high-technology firms weighted by the share of hightechnology sellers in the economy. The share of high-technology firms is the sum of the share of domestic $N_{D A} / N$ and of foreign high-technology firms $N_{X A}^{*} / N$. The third term corresponds to difference between export and domestic prices weighted with the share of foreign firms in the economy. Because of tougher selection (lower $c_{D}$ ), the average price of low-technology firms is lower in the foreign country (first term). The fraction of hightechnology sellers and the fraction of foreign firms might be higher in either country. Hence, 


\begin{tabular}{lcc} 
& Home & Foreign \\
\hline$N_{A} / N$ & 0.1822 & 0.1608 \\
$N_{X}^{*} / N$ & 0.8086 & 0.1231 \\
$\bar{p}$ & 7.0329 & 6.81622 \\
$N$ & 1.7286 & 1.9592 \\
$\sigma_{p}^{2}$ & 0.7661 & 0.8330 \\
$W$ & 1.1882 & 1.2203 \\
\hline
\end{tabular}

Table 1: $\left(\tau=0.8, t=0.5, k=2.5, \gamma=0.2, S=1, f=f_{E}=c_{M}=10, \psi=1.25\right)$

it is a priori unclear if the average price is higher in the home country or in the foreign country.

The number of firms in each country is given by:

$N=\frac{\frac{\alpha}{\beta} \frac{\left(\alpha-c_{D}\right) c_{D}^{*}}{2(k+1)}+\frac{t}{2} \frac{1}{D}\left[\left(c_{D}\right)^{k}\left(c_{A}^{*}\right)^{k}-\left(c_{X}^{*}\right)^{k}\left(c_{A}\right)^{k}\right] \frac{\alpha}{\beta}\left(c_{D}^{*}-c_{D}\right)+\frac{\alpha}{\beta} \frac{\tau\left(c_{X}\right)^{k}}{2 D(k+1)}\left[\left(\alpha-c_{D}\right)\left(c_{X}\right)^{k}+\left(\alpha-c_{D}^{*}\right)\left(c_{D}\right)^{k}\right]}{\frac{c_{D} c_{D}^{*}}{4(k+1)^{2}}+\frac{t}{4(k+1) D} \Delta+\frac{t \tau}{4 D(k+1)} \Theta}$,

where

$$
\begin{aligned}
& D=\left(c_{D}\right)^{k}\left(c_{D}^{*}\right)^{k}-\left(c_{D}-\tau\right)^{k}\left(c_{D}^{*}-\tau\right)^{k} \\
& \Delta=c_{D}\left\{\left(c_{D}\right)^{k}\left(c_{A}^{*}\right)^{k}-\left(c_{X}^{*}\right)^{k}\left[\left(c_{A}\right)^{k}-\frac{\tau\left(c_{X}\right)^{k}}{t(k+1)}\right]\right\}+c_{D}^{*}\left\{\left(c_{D}^{*}\right)^{k}\left(c_{A}\right)^{k}-\left(c_{X}\right)^{k}\left[\left(c_{A}^{*}\right)^{k}-\frac{\tau\left(c_{X}^{*}\right)^{k}}{t(k+1)}\right]\right\} \\
& \Theta=\left[\left(c_{X}\right)^{k}\left(c_{A}^{*}\right)^{k}+\left(c_{X}^{*}\right)^{k}\left(c_{A}\right)^{k}-\frac{\tau\left(c_{X}\right)^{k}\left(c_{D}^{*}\right)^{k}}{t(k+1)}\right] .
\end{aligned}
$$

The price variance $\sigma_{p}^{2}$ is the sum of the price variances of domestic and foreign sellers weighted with their shares in the total population of sellers:

$$
\sigma_{p}^{2}=\frac{N^{D}}{N} \sigma_{p, d o m}^{2}+\frac{N^{X}}{N} \sigma_{p, e x p}^{2}
$$

We use the basic specification above to assess the overall impact of credit constraints on average price, number of sellers, price variance, and welfare. Table 1 shows that the fraction of high-technology sellers $N_{A} / N$ is higher in the home country. This is due to the large fraction of high-technology firms that export from the foreign to the home country. However, a higher average price of low-technology firms leads to a higher average price and, together with a lower number of sellers, to lower welfare in the home country.

We next use the basic specification to study the effect of a 5\%-decrease in trade costs $\tau$ on welfare in the two countries. Table 2 shows the simulation results for welfare and the 


\begin{tabular}{l|cccccccc}
$\tau$ & $\bar{p}$ & $\overline{p^{*}}$ & $N$ & $N^{*}$ & $\sigma_{p}^{2}$ & $\left(\sigma_{p}^{2}\right)^{*}$ & $W$ & $W^{*}$ \\
\hline 1.0000 & 7.0922 & 6.9202 & 1.7094 & 1.8904 & 0.7692 & 0.8270 & 1.1825 & 1.2075 \\
0.9500 & 7.0771 & 6.8956 & 1.7150 & 1.9065 & 0.7683 & 0.8280 & 1.1840 & 1.2105 \\
0.9025 & 7.0629 & 6.8715 & 1.7199 & 1.9224 & 0.7675 & 0.8292 & 1.1854 & 1.2134 \\
0.8574 & 7.0495 & 6.8477 & 1.7241 & 1.9382 & 0.7668 & 0.8307 & 1.1867 & 1.2164 \\
0.8145 & 7.0371 & 6.8243 & 1.7276 & 1.9538 & 0.7663 & 0.8324 & 1.1878 & 1.2193 \\
0.7738 & 7.0255 & 6.8013 & 1.7302 & 1.9693 & 0.7659 & 0.8343 & 1.1889 & 1.2222 \\
0.7351 & 7.0147 & 6.7786 & 1.7321 & 1.9846 & 0.7656 & 0.8364 & 1.1899 & 1.2252 \\
\hline \hline$\tau$ & $\bar{p} / p^{*}$ & $N / N^{*}$ & $\sigma_{p}^{2} /\left(\sigma_{p}^{2}\right)^{*}$ & $W / W^{*}$ \\
\hline 1.0000 & 1.0249 & 0.9043 & 0.9301 & 0.9793 \\
0.9500 & 1.0263 & 0.8996 & 0.9279 & 0.9781 \\
0.9025 & 1.0279 & 0.8947 & 0.9256 & 0.9769 \\
0.8574 & 1.0295 & 0.8895 & 0.9231 & 0.9756 \\
0.8145 & 1.0312 & 0.8842 & 0.9206 & 0.9742 \\
0.7738 & 1.0330 & 0.8786 & 0.9181 & 0.9728 \\
0.7351 & 1.0349 & 0.8727 & 0.9154 & 0.9712 \\
\hline
\end{tabular}

Table 2: Impact of a 5\%-decrease in trade costs on welfare

$\left(t=0.5, k=2.5, \gamma=0.2, S=1, f=f_{E}=c_{M}=10, \psi=1.25\right)$

three variables that determine welfare $\left(\bar{p}, N, \sigma_{p}^{2}\right)$.

A reduction in trade costs $\tau$ increases the number of varieties in both countries. However, $N$ increases less than $N^{*}$. The average price decreases in both markets but it decreases more in the foreign country. The price variance that positively affects welfare increases more in the foreign country. Hence, welfare increases in both countries but the welfare increase is larger in the foreign country. The welfare gap between the two countries thus widens.

From section 4.2, we know that the average productivity gap increases, too. Table 3 shows the simulation results for aggregate production cost, our (inverse) measures of aggregate productivity, where $\overline{C o P}_{q}, \overline{C o P_{q}^{*}}$ denotes weighting with demand $q(c)$ and $\overline{C o P}_{r}, \overline{C o P_{r}^{*}}$ describes weighting by revenues $r(c)$. Both measures of aggregate production cost decrease after trade liberalization and more so in the foreign country, that is relative aggregate costs increase. We interpret this result as an increase in the aggregate productivity gap.

\section{Conclusion}

Even though recommended to many developing countries, only if certain conditions are met does opening up to trade enhance economic convergence. This paper examines the role of credit market imperfections as a reason for a potentially detrimental effect of trade liberalization on convergence. In particular, we introduce the possibility of investing in a 


\begin{tabular}{l|cccccc} 
& \multicolumn{3}{|c}{ Average productivity } & \multicolumn{4}{c}{ Aggregate productivity } \\
$\tau$ & $\overline{C o P}$ & $\overline{C_{o P}^{*}}$ & $\overline{C_{o} P_{q}}$ & $\overline{C_{o} P_{q}^{*}}$ & $\overline{C_{o} P_{r}}$ & $\overline{C_{o} P_{r}^{*}}$ \\
\hline 1.0000 & 5.8301 & 5.6914 & 26.3507 & 25.3051 & 177.0300 & 165.1811 \\
0.9500 & 5.8183 & 5.6737 & 26.244 & 25.1547 & 175.9566 & 163.6664 \\
0.9025 & 5.8071 & 5.6565 & 26.1434 & 25.0084 & 174.9478 & 162.1963 \\
0.8574 & 5.7966 & 5.6398 & 26.0491 & 24.8658 & 174.0027 & 160.7685 \\
0.8145 & 5.7867 & 5.6233 & 25.9609 & 24.7267 & 173.1202 & 159.3807 \\
0.7738 & 5.7775 & 5.6073 & 25.8786 & 24.5911 & 172.2992 & 158.0304 \\
0.7351 & 5.7690 & 5.5915 & 25.8023 & 24.4585 & 171.5386 & 156.7151 \\
\hline \hline$\tau$ & $\overline{C o P} / \overline{C o P^{*}}$ & $\overline{C o P_{q}} / \overline{C_{o} P_{q}^{*}}$ & $\overline{C o P_{r}} / \overline{C_{o} P_{r}^{*}}$ \\
\hline 1.0000 & 1.0244 & 1.0413 & 1.0717 \\
0.9500 & 1.0255 & 1.0433 & 1.0751 \\
0.9025 & 1.0266 & 1.0454 & 1.0786 \\
0.8574 & 1.0278 & 1.0476 & 1.0823 \\
0.8145 & 1.0291 & 1.0499 & 1.0862 \\
0.7738 & 1.0304 & 1.0524 & 1.0903 \\
0.7351 & 1.0317 & 1.0549 & 1.0946 \\
\hline
\end{tabular}

Table 3: Impact of a 5\%-decrease in trade costs on productivity $\left(t=0.5, k=2.5, \gamma=0.2, S=1, f=f_{E}=c_{M}=10, \psi=1.25\right)$

more efficient technology into a two-country heterogeneous-firm model with variable markups. The two countries may differ with respect to credit market development: in the less developed country, firms face credit constraints and therefore higher costs of technology upgrading. As a consequence, credit constrained firms cannot take advantage of the larger market to the same extent but face fiercer increased import competition. Therefore, the difference between the two countries with respect to the fraction of domestic firms that invest in advanced technology increases. Hence, the productivity gap between the two countries widens. Moreover, our simulations show that the welfare gap also increases after trade liberalization.

Our focus is on the interplay of trade liberalization and credit market frictions because credit market deficiencies are a major obstacle to achieving convergence. However, our model could naturally be extended to the analysis of other market imperfections.

Our results have important policy implications. Trade liberalization fosters convergence if and only if firms in emerging countries have equal access to external finance. In order to reduce the productivity gap, a reduction in trade barriers must thus be accompanied by credit market development. In our model, small and medium-sized firms might have an incentive to invest in technology adoption but are prevented from doing so by high costs of external finance. Policies aimed at increasing the access of smaller firms to external finance 
are therefore expected to have a strong effect.

Our model has abstracted from several important considerations. First, we assume a quasi-linear utility function that allows normalizing the wage to unity. In doing so, we ignore the effect that trade liberalization might have on (relative) wages (e.g. Bustos, 2011). Second, we abstract from the possibility that firms serve the foreign market through foreign direct investment. An interesting extension would thus be to include knowledge spillovers from foreign to domestic producers. Third, we focus on technology adoption and do not consider product innovation. However, following Atkeson and Burstein (2010), we can interpret entry into the differentiated good industry as product innovation. Our model then shows that trade liberalization increases the divergence between developed and less developed country in product innovation activity. 


\section{Mathematical Appendix}

\section{Proof of Lemma 1.}

Totally differentiating (19) respectively yields the slopes of the free entry conditions of the home country and of the foreign country in the $\left(c_{D}, c_{D}^{*}\right)$ space:

$$
\begin{aligned}
& \text { Slope } F E: \frac{d c_{D}^{*}}{d c_{D}}=-\frac{\left(c_{D}\right)^{k+1}+t(k+1)\left(c_{A}\right)^{k}}{\left(c_{D}^{*}-\tau\right)^{k+1}+t(k+1)\left(c_{A}\right)^{k}} \\
& \text { Slope } F E^{*}: \frac{d c_{D}^{*}}{d c_{D}}=-\frac{\left(c_{D}-\tau\right)^{k+1}+t(k+1)\left(c_{A}^{*}\right)^{k}}{\left(c_{D}^{*}\right)^{k+1}+t(k+1)\left(c_{A}^{*}\right)^{k}} .
\end{aligned}
$$

Both curves are downward sloping. From our assumption that $c_{X}<c_{D}$ follows that $\left(c_{X}\right)^{k}<\left(c_{D}\right)^{k}$. The slope of FE is unambiguously larger than one and the slope of $F E^{*}$ is unambiguously smaller than one. Hence, there is a unique intersection if the two curves intersect.

For given $\left(\psi, \psi^{*}\right)$ let $c_{D}(1)$ denote the solution to home's free entry condition for $c_{D}^{*}=c_{M}$. Furthermore, denote with $\bar{\psi}$ the value of $\psi$, given $\psi^{*}$, for which $\left(c_{D}(1), c_{M}\right)$ is the solution to foreign's free entry condition. It follows that for $\psi<\bar{\psi}$ and, by symmetry, for $\psi^{*}<\bar{\psi}$ the two curves intersect.

\section{Proof of Proposition 1}

\section{Entry cutoffs}

The RHS of the two free entry conditions is identical. For a given entry cutoff in the other country, (i) the LHS monotonously increases in the own entry cutoff and (ii) the LHS of (19) is larger in the foreign country. Therefore, $c_{D}^{*}<c_{D}$.

\section{Average productivity}

From (18) the average cost of domestic firms, our (inverse) measure of average productivity, are

$$
\overline{C o P}=\frac{k}{k+1} c_{D}-t\left(\frac{c_{A}}{c_{D}}\right)^{k} .
$$

Since $c_{D}^{*}<c_{D}$ and, from (14), $c_{A}^{*}>c_{A}, \overline{C o P}^{*}<\overline{C o P}$, that is average productivity is higher in the foreign country.

Aggregate production cost is obtained by weighting production cost either with output $q(c)$ 
or with revenues $r(c)$ :

$$
\begin{aligned}
\overline{C o P_{q}} & =\frac{N_{D A}}{N_{D}} \int_{0}^{c_{A}}(c-t) q^{A}(c) \frac{g(c)}{G\left(c_{A}\right)} d c+\frac{N_{D L}}{N_{D}} \int_{c_{A}}^{c_{D}} c q(c) \frac{g(c)}{G\left(c_{D}\right)-G\left(c_{A}\right)} d c \\
& =\frac{S}{2 \gamma}\left\{\frac{k\left(c_{D}\right)^{2}}{(k+1)(k+2)}-t\left(\frac{c_{A}}{c_{D}}\right)^{k}\left[c_{D}-\frac{2 k}{k+1} c_{A}+t\right]\right\} \\
\overline{C o P_{r}} & =\frac{N_{D A}}{N_{D}} \int_{0}^{c_{A}}(c-t) r^{A}(c) \frac{g(c)}{G\left(c_{A}\right)} d c+\frac{N_{D L}}{N_{D}} \int_{c_{A}}^{c_{D}} c r(c) \frac{g(c)}{G\left(c_{D}\right)-G\left(c_{A}\right)} d c \\
& =\frac{S}{4 \gamma}\left\{\frac{2 k\left(c_{D}\right)^{3}}{(k+1)(k+3)}-t \frac{\left(c_{A}\right)^{k}}{\left(c_{D}\right)^{k-2}}-\frac{t^{2} k\left(c_{A}\right)^{k+1}}{(k+1)(k+2)\left(c_{D}\right)^{k}}\left[(k+2)-(k+1) c_{A}\right]+t^{3}\right\} .
\end{aligned}
$$

Fraction of exporters and high-technology firms

From (13) and (14) follows directly that $\left(\frac{c_{X}}{c_{D}}\right)^{k}<\left(\frac{c_{X}^{*}}{c_{D}^{*}}\right)^{k}$ and $\left(\frac{c_{A}}{c_{D}}\right)^{k}<\left(\frac{c_{A}^{*}}{c_{D}^{*}}\right)^{k}$ : the fraction of exporters and high-technology firms is larger in the foreign country.

\section{Divergence}

Totally differentiating (19) yields $\frac{d c_{D}}{d \psi}>0$ and $\frac{d c_{D}^{*}}{d \psi}<0$. Intuitively, given $\psi^{*}$, an increase in $\psi$ lowers (increases) ex-ante expected profits in the home (foreign) country leading to less (more) entry and hence to a higher (lower) entry cutoff. Furthermore, $\frac{d c_{X}}{d \psi}=\frac{d c_{D}^{*}}{d \psi}<0$, $\frac{d c_{X}^{*}}{d \psi}=\frac{d c_{D}}{d \psi}>0, \frac{d c_{A}}{d \psi}=\frac{d c_{D}}{d \psi}+\frac{d c_{D}^{*}}{d \psi}-\frac{2 \gamma f}{S t}<0$ and $\frac{d c_{A}^{*}}{d \psi}=\frac{d c_{D}}{d \psi}+\frac{d c_{D}^{*}}{d \psi}>0$. It follows that $\overline{C o P}-\overline{C o P}^{*},\left(\frac{c_{X}^{*}}{c_{D}^{*}}\right)^{k}-\left(\frac{c_{X}}{c_{D}}\right)^{k}$ and $\left(\frac{c_{A}^{*}}{c_{D}^{*}}\right)^{k}-\left(\frac{c_{A}}{c_{D}}\right)^{k}$ increase. Moreover:

$$
\begin{aligned}
& \frac{d\left[\left(\frac{c_{X}^{*}}{c_{D}^{*}}\right)^{k} /\left(\frac{c_{X}}{c_{D}}\right)^{k}\right]}{d \psi}=k\left(\frac{c_{X}^{*} c_{D}}{c_{D}^{*} c_{X}}\right)^{k} \frac{\left[c_{D} \frac{d c_{X}^{*}}{d \psi}+c_{X}^{*} \frac{d c_{D}}{d \psi}\right] c_{D}^{*} c_{X}-\left[c_{X} \frac{d c_{D}^{*}}{d \psi}+c_{D}^{*} \frac{d c_{X}}{d \psi}\right] c_{D} c_{X}^{*}}{\left(c_{D}^{*} c_{X}\right)^{2}} \\
& =k\left(\frac{c_{X}^{*} c_{D}}{c_{D}^{*} c_{X}}\right)^{k} \frac{\left(c_{D}+c_{X}^{*}\right) \frac{d c_{D}}{d \psi} c_{D}^{*} c_{X}-\left(c_{X}+c_{D}^{*}\right) \frac{d c_{D}^{*}}{d \psi} c_{D} c_{X}^{*}}{\left(c_{D}^{*} c_{X}\right)^{2}}>0 \\
& \frac{d\left[\left(\frac{c_{A}^{*}}{c_{D}^{*}}\right)^{k} /\left(\frac{c_{A}}{c_{D}}\right)^{k}\right]}{d \psi}=k\left(\frac{c_{A}^{*} c_{D}}{c_{D}^{*} c_{A}}\right)^{k} \frac{\left[c_{D} \frac{d c_{A}^{*}}{d \psi}+c_{A}^{*} \frac{d c_{D}}{d \psi}\right] c_{D}^{*} c_{A}-\left[c_{A} \frac{d c_{D}^{*}}{d \psi}+c_{D}^{*} \frac{d c_{A}}{d \psi}\right] c_{D} c_{A}^{*}}{\left(c_{D}^{*} c_{A}\right)^{2}} \\
& =k\left(\frac{c_{A}^{*} c_{D}}{c_{D}^{*} c_{A}}\right)^{k} \frac{\left[c_{D}\left(\frac{d c_{D}}{d \psi}+\frac{d c_{D}^{*}}{d \psi}\right)+c_{A}^{*} \frac{d c_{D}}{d \psi}\right] c_{D}^{*} c_{A}-\left[c_{A} \frac{d c_{D}^{*}}{d \psi}+c_{D}^{*}\left(\frac{d c_{D}}{d \psi}+\frac{d c_{D}^{*}}{d \psi}-\frac{2 \gamma f}{S t}\right)\right] c_{D} c_{A}^{*}}{\left(c_{D}^{*} c_{A}\right)^{2}}>0 \\
& \frac{d\left(\overline{C o P} / \overline{C o P^{*}}\right)}{d \psi}=\frac{\left[\frac{k}{k+1} \frac{d c_{D}}{d \psi}-t k\left(\frac{c_{A}}{c_{D}}\right)^{k-1} \frac{\frac{d c_{A}}{d \psi} c_{D}-\frac{d c_{D}}{d \psi} c_{A}}{\left(c_{D}\right)^{2}}\right] \overline{C o P^{*}}}{(\overline{C o P})^{2}}-\frac{\left[\frac{k}{k+1} \frac{d c_{D}^{*}}{d \psi}-t k\left(\frac{c_{A}^{*}}{c_{D}^{*}}\right)^{k-1} \frac{\frac{d c_{A}^{*}}{d \psi} c_{D}^{*}-\frac{d c_{D}^{*}}{d \psi} c_{A}^{*}}{\left(c_{D}^{*}\right)^{2}}\right] \overline{C o P}}{(\overline{C o P})^{2}}>0 .
\end{aligned}
$$

\section{Proof of Proposition 2}


Fraction of exporters and high-technology firms

In the symmetric case, $\psi=\psi^{*}$. The free entry condition (19) reduces to:

$$
\frac{\left(c_{D}\right)^{k+2}+\left(c_{D}-\tau\right)^{k+2}}{k+2}+2 t\left(c_{A}\right)^{k+1}=\frac{f_{E} 2 \gamma c_{M}^{k}(k+1)}{S} .
$$

Totally differentiating (A.5) yields

$$
\frac{d c_{D}}{d \tau}=\frac{\left(c_{D}-\tau\right)^{k+1}+t(k+1)\left(c_{A}\right)^{k}}{\left(c_{D}\right)^{k+1}+\left(c_{D}-\tau\right)^{k+1}+2 t(k+1)\left(c_{A}\right)^{k}} .
$$

$c_{X}$ then decreases in $\tau$ :

$$
\begin{aligned}
\frac{d c_{X}}{d \tau} & =\frac{d c_{D}}{d \tau}-1<0 \\
& \leftrightarrow-\left(c_{D}\right)^{k+1}-t(k+1)\left(c_{A}\right)^{k}<0
\end{aligned}
$$

Since $c_{D}$ increases in $\tau$, the fraction of exporters, given by $\left(\frac{c_{X}}{c_{D}}\right)^{k}$ unambiguously decreases in $\tau$.

$c_{A}$ decreases in $\tau$

$$
\begin{aligned}
\frac{d c_{A}}{d \tau} & =\frac{1}{2}\left(2 \frac{d c_{D}}{d \tau}-1\right)<0 \\
& \leftrightarrow\left(c_{D}-\tau\right)^{k+1}-\left(c_{D}\right)^{k+1}<0 .
\end{aligned}
$$

The fraction of high-technology firms also unambiguously decreases in $\tau$.

\section{Proof of Proposition 3}

Entry cutoffs

Totally differentiating the free entry conditions yields the following expressions:

$$
\begin{aligned}
\frac{d c_{D}}{d \tau} & =\frac{\left[\left(c_{X}\right)^{k+1}+t(k+1)\left(c_{A}\right)^{k}\right]\left[\left(c_{D}^{*}\right)^{k+1}-\left(c_{X}^{*}\right)^{k+1}\right]}{\left[\left(c_{D}\right)^{k+1}+t(k+1)\left(c_{A}\right)^{k}\right]\left[\left(c_{D}^{*}\right)^{k+1}+t(k+1)\left(c_{A}^{*}\right)^{k}\right]-\left[\left(c_{X}\right)^{k+1}+t(k+1)\left(c_{A}\right)^{k}\right]\left[\left(c_{X}^{*}\right)^{k+1}+t(k+1)\left(c_{A}^{*}\right)^{k}\right]} \\
\frac{d c_{D}^{*}}{d \tau} & =\frac{\left[\left(c_{X}^{*}\right)^{k+1}+t(k+1)\left(c_{A}^{*}\right)^{k}\right]\left[\left(c_{D}\right)^{k+1}-\left(c_{X}\right)^{k+1}\right]}{\left[\left(c_{D}^{*}\right)^{k+1}+t(k+1)\left(c_{A}^{*}\right)^{k}\right]\left[\left(c_{D}\right)^{k+1}+t(k+1)\left(c_{A}\right)^{k}\right]-\left[\left(c_{X}^{*}\right)^{k+1}+t(k+1)\left(c_{A}^{*}\right)^{k}\right]\left[\left(c_{X}\right)^{k+1}+t(k+1)\left(c_{A}\right)^{k}\right]} .
\end{aligned}
$$

Hence, $\frac{d c_{D}}{d \tau}>0, \frac{d c_{D}^{*}}{d \tau}>0$, and $\frac{d c_{D}}{d \tau}<\frac{d c_{D}^{*}}{d \tau}$. Moreover, $\frac{d c_{D}}{d \tau}+\frac{d c_{D}^{*}}{d \tau}<1$.

Average productivity, fraction of exporters and high-technology firms 
From (A.7) follows that $\frac{d c_{X}}{d \tau}=\frac{d c_{D}^{*}}{d \tau}-1<0, \frac{d c_{X}^{*}}{d \tau}=\frac{d c_{D}}{d \tau}-1<0$. Moreover, $\frac{d c_{A}}{d \tau}=\frac{d c_{A}^{*}}{d \tau}=$ $\frac{1}{2}\left(\frac{d c_{D}}{d \tau}+\frac{d c_{D}^{*}}{d \tau}-1\right)<0$.

It follows that the difference between the countries with respect to average productivity of domestic firms, the fraction of exporters and the fraction of high-technology firms decreases in $\tau$.

Moreover:

$$
\begin{aligned}
\frac{d\left[\left(\frac{c_{X}^{*}}{c_{D}^{*}}\right)^{k} /\left(\frac{c_{X}}{c_{D}}\right)^{k}\right]}{d \tau}= & k\left(\frac{c_{X}^{*} c_{D}}{c_{D}^{*} c_{X}}\right)^{k} \frac{\left[c_{D} \frac{d c_{X}^{*}}{d \tau}+c_{X}^{*} \frac{d c_{D}}{d \tau}\right] c_{D}^{*} c_{X}-\left[c_{X} \frac{d c_{D}^{*}}{d \tau}+c_{D}^{*} \frac{d c_{X}}{d \tau}\right] c_{D} c_{X}^{*}}{\left(c_{D}^{*} c_{X}\right)^{2}}><0 \\
\frac{d\left[\left(\frac{c_{A}^{*}}{c_{D}^{*}}\right)^{k} /\left(\frac{c_{A}}{c_{D}}\right)^{k}\right]}{d \tau}= & k\left(\frac{c_{A}^{*} c_{D}}{c_{D}^{*} c_{A}}\right)^{k} \frac{\left[c_{D} \frac{d c_{A}^{*}}{d \tau}+c_{A}^{*} \frac{d c_{D}}{d \tau}\right] c_{D}^{*} c_{A}-\left[c_{A} \frac{d c_{D}^{*}}{d \tau}+c_{D}^{*} \frac{d c_{A}}{d \tau}\right] c_{D} c_{A}^{*}}{\left(c_{D}^{*} c_{A}\right)^{2}}><0 \\
\frac{d\left(\overline{C o P} / \overline{C o P^{*}}\right)}{d \tau}= & \left.\frac{\left[\frac{k}{k+1} \frac{d c_{D}}{d \tau}-t k\left(\frac{c_{A}}{c_{D}}\right)^{k-1} \frac{\frac{d c_{A}}{d \tau} c_{D}-\frac{d c_{D}}{d \tau} c_{A}}{\left(c_{D}\right)^{2}}\right] \overline{C o P^{*}}}{\left(\overline{C o P^{*}}\right)^{2}}-\frac{k}{k+1} \frac{d c_{D}^{*}}{d \tau}-t k\left(\frac{c_{A}^{*}}{c_{D}^{*}}\right)^{k-1} \frac{\left.\frac{d c_{A}^{*}}{d \tau} c_{D}^{*}-\frac{d c_{D}^{*}}{d \tau} c_{A}^{*}\right]}{\left(c_{D}^{*}\right)^{2}}\right] \frac{(\overline{C o P})^{*}}{C o P} \\
= & \frac{k}{\left(\overline{C o P^{*}}\right)^{2}(k+1)}\left[\frac{d c_{D}}{d \tau} \overline{C o P^{*}}-\frac{d c_{D}^{*}}{d \tau} \overline{C o P}\right]-\frac{t k}{\left(\overline{C o P^{*}}\right)^{2}}\left\{\frac{d c_{A}}{d \tau}\left[\left(\frac{c_{A}}{c_{D}}\right)^{k-1} \frac{\overline{C O P}^{*}}{c_{D}}-\left(\frac{c_{A}^{*}}{c_{D}^{*}}\right)^{k-1} \frac{\overline{C o P}}{c_{D}^{*}}\right]\right. \\
& \left.-\left[\left(\frac{c_{A}}{c_{D}}\right)^{k} \frac{\overline{C o P}}{c_{D}} \frac{d c_{D}}{d \tau}-\left(\frac{c_{A}^{*}}{c_{D}^{*}}\right)^{k} \frac{\overline{C o P}}{c_{D}^{*}} \frac{d c_{D}^{*}}{d \tau}\right]\right\}<0 .
\end{aligned}
$$

\section{Welfare Analysis}

\section{Average price}

The average price of varieties sold in the home country is the sum of the average price of domestic and the average price of foreign sellers weighted with their share in the total population of sellers:

$$
\bar{p}=\frac{N_{D}}{N} \bar{p}_{d o m}+\frac{N_{X}^{*}}{N} \bar{p}_{e x p}^{*}
$$

where $N, N_{D}$ and $N_{X}^{*}$ are the total number of sellers, the number of domestic sellers and the number of foreign sellers in the home country. The average price in the foreign country is analogous.

Moreover:

(1) The number of sellers in each market is the sum of domestic and foreign sellers:

$$
\begin{aligned}
N & =G\left(c_{D}\right) N_{E}+G\left(c_{X}^{*}\right) N_{E}^{*} \\
N^{*} & =G\left(c_{D}^{*}\right) N_{E}^{*}+G\left(c_{X}\right) N_{E} .
\end{aligned}
$$


(A.10) can be solved for the number of entrants $N_{E}$ and $N_{E}^{*}$ :

$$
\begin{aligned}
& N_{E}=\frac{\left(c_{M}\right)^{k}}{\left(c_{D}\right)^{k}\left(c_{D}^{*}\right)^{k}-\left(c_{D}-\tau\right)^{k}\left(c_{D}^{*}-\tau\right)^{k}}\left[N\left(c_{D}^{*}\right)^{k}-N^{*}\left(c_{D}-\tau\right)^{k}\right] \\
& N_{E}^{*}=\frac{\left(c_{M}\right)^{k}}{\left(c_{D}\right)^{k}\left(c_{D}^{*}\right)^{k}-\left(c_{D}-\tau\right)^{k}\left(c_{D}^{*}-\tau\right)^{k}}\left[N^{*}\left(c_{D}\right)^{k}-N\left(c_{D}^{*}-\tau\right)^{k}\right] .
\end{aligned}
$$

Using (A.11), the fraction of domestic and foreign producers is then

$$
\begin{gathered}
\frac{N_{D}}{N}=\frac{1}{\left(c_{D}\right)^{k}\left(c_{D}^{*}\right)^{k}-\left(c_{D}-\tau\right)^{k}\left(c_{D}^{*}-\tau\right)^{k}}\left[\left(c_{D}\right)^{k}\left(c_{D}^{*}\right)^{k}-\frac{N^{*}}{N}\left(c_{D}\right)^{k}\left(c_{D}-\tau\right)^{k}\right] \\
\frac{N_{X}^{*}}{N}=\frac{1}{\left(c_{D}\right)^{k}\left(c_{D}^{*}\right)^{k}-\left(c_{D}-\tau\right)^{k}\left(c_{D}^{*}-\tau\right)^{k}}\left[\frac{N^{*}}{N}\left(c_{D}-\tau\right)^{k}\left(c_{D}\right)^{k}-\left(c_{D}-\tau\right)^{k}\left(c_{D}^{*}-\tau\right)^{k}\right](A
\end{gathered}
$$

(2) The average price of domestic sellers is the sum of the average price of domestic low- and high-technology firms weighted with their share in the total population of domestic sellers, $\frac{N_{D L}}{N_{D}}=\frac{G\left(c_{D}\right)-G\left(c_{A}\right)}{G\left(c_{D}\right)}$ and $\frac{N_{D A}}{N_{D}}=\frac{G\left(c_{A}\right)}{G\left(c_{D}\right)}$ :

$$
\begin{aligned}
\bar{p}_{d o m} & =\frac{N_{D A}}{N_{D}} \int_{0}^{c_{A}} p_{D A} \frac{g(c)}{G\left(c_{A}\right)} d c+\frac{N_{D L}}{N_{D}} \int_{c_{A}}^{c_{D}} p_{D} \frac{g(c)}{G\left(c_{D}\right)-G\left(c_{A}\right)} d c \\
& =\frac{2 k+1}{2(k+1)} c_{D}-\frac{t}{2}\left(\frac{c_{A}}{c_{D}}\right)^{k} .
\end{aligned}
$$

Analogously, the average price of foreign sellers is the sum of the average price of foreign low- and high-technology firms weighted with their share in the total population of foreign sellers, $\frac{N_{X}^{*}}{N_{X}^{*}}=\frac{G\left(c_{X}^{*}\right)-G\left(c_{A}^{*}\right)}{G\left(c_{X}^{*}\right)}$ and $\frac{N_{X}^{*}}{N_{X}^{*}}=\frac{G\left(c_{A}^{*}\right)}{G\left(c_{X}^{*}\right)}$;

$$
\begin{aligned}
\bar{p}_{e x p}^{*} & =\frac{N_{X A}^{*}}{N_{X}^{*}} \int_{0}^{c_{A}^{*}} p_{X A}^{*} \frac{g(c)}{G\left(c_{A}^{*}\right)} d c+\frac{N_{X L}^{*}}{N_{X}^{*}} \int_{c_{A}^{*}}^{c_{X}^{*}} p_{X}^{*} \frac{g(c)}{G\left(c_{X}^{*}\right)-G\left(c_{A}^{*}\right)} d c \\
& =\frac{2 k+1}{2(k+1)} c_{D}-\frac{t}{2}\left(\frac{c_{A}^{*}}{c_{X}^{*}}\right)^{k}+\frac{\tau}{2(k+1)}
\end{aligned}
$$

Substituting (A.12), (A.13) and (A.14) into (A.9) gives

$$
\bar{p}=\frac{2 k+1}{2(k+1)} c_{D}-\frac{t}{2}\left\{\frac{N_{D}}{N}\left(\frac{c_{A}}{c_{D}}\right)^{k}+\frac{N_{X}^{*}}{N}\left[\left(\frac{c_{A}^{*}}{c_{X}^{*}}\right)^{k}-\frac{\tau}{2(k+1)}\right]\right\} .
$$

Number of firms in the market 
From (11) follows

$$
\bar{p}=c_{D}-\frac{\gamma\left(\alpha-c_{D}\right)}{\beta N} .
$$

Equating (A.16) with (A.15) yields the following expression for the $N$ :

$$
N=\frac{\frac{\gamma}{\beta}\left(\alpha-c_{D}\right)-\frac{t}{2} \frac{1}{\left(c_{D}\right)^{k}\left(c_{D}^{*}\right)^{k}-\left(c_{D}-\tau\right)^{k}\left(c_{D}^{*}-\tau\right)^{k}} N^{*}\left\{\left(c_{D}\right)^{k}\left[\left(c_{A}^{*}\right)^{k}-\frac{\tau\left(c_{D}-\tau\right)^{k}}{t(k+1)}\right]-\left(c_{D}-\tau\right)^{k}\left(c_{A}\right)^{k}\right\}}{\frac{c_{D}}{2(k+1)}+\frac{t}{2} \frac{1}{\left(c_{D}\right)^{k}\left(c_{D}^{*}\right)^{k}-\left(c_{D}-\tau\right)^{k}\left(c_{D}^{*}-\tau\right)^{k}}\left\{\left(c_{D}^{*}\right)^{k}\left(c_{A}\right)^{k}-\left(c_{D}^{*}-\tau\right)^{k}\left[\left(c_{A}^{*}\right)^{k}-\frac{\tau\left(c_{D}-\tau\right)^{k}}{t(k+1)}\right]\right\}} .
$$

The expression for $N^{*}$ is symmetric:

$$
N^{*}=\frac{\frac{\gamma}{\beta}\left(\alpha-c_{D}^{*}\right)-\frac{t}{2} \frac{1}{\left(c_{D}\right)^{k}\left(c_{D}^{*}\right)^{k}-\left(c_{D}-\tau\right)^{k}\left(c_{D}^{*}-\tau\right)^{k}} N\left\{\left(c_{D}^{*}\right)^{k}\left[\left(c_{A}\right)^{k}-\frac{\tau\left(c_{D}^{*}-\tau\right)^{k}}{t(k+1)}\right]-\left(c_{D}^{*}-\tau\right)^{k}\left(c_{A}^{*}\right)^{k}\right\}}{\frac{c_{D}^{*}}{2(k+1)}+\frac{t}{2} \frac{1}{\left(c_{D}\right)^{k}\left(c_{D}^{*}\right)^{k}-\left(c_{D}-\tau\right)^{k}\left(c_{D}^{*}-\tau\right)^{k}}\left\{\left(c_{D}\right)^{k}\left(c_{A}^{*}\right)^{k}-\left(c_{D}-\tau\right)^{k}\left[\left(c_{A}\right)^{k}-\frac{\tau\left(c_{D}^{*}-\tau\right)^{k}}{t(k+1)}\right]\right\}} .
$$

Plugging (A.17) into (A.18) gives

$$
\begin{aligned}
& N=\frac{\frac{\gamma}{\beta} \frac{\left(\alpha-c_{D}\right) c_{D}^{*}}{2(k+1)}+\frac{t}{2} \frac{1}{D}\left[\left(c_{D}\right)^{k}\left(c_{A}^{*}\right)^{k}-\left(c_{X}^{*}\right)^{k}\left(c_{A}\right)^{k}\right] \frac{\gamma}{\beta}\left(c_{D}^{*}-c_{D}\right)+\frac{\gamma}{\beta} \frac{\tau\left(c_{X}^{*}\right)^{k}}{2 D(k+1)}\left[\left(\alpha-c_{D}\right)\left(c_{X}\right)^{k}+\left(\alpha-c_{D}^{*}\right)\left(c_{D}\right)^{k}\right]}{\frac{c_{D} c_{D}^{*}}{4(k+1)^{2}}+\frac{t}{4(k+1) D} \Delta+\frac{t \tau}{4 D(k+1)} \Theta}
\end{aligned}
$$

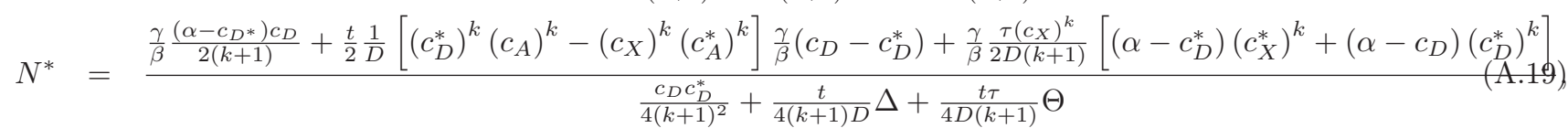

where

$$
\begin{aligned}
& D=\left(c_{D}\right)^{k}\left(c_{D}^{*}\right)^{k}-\left(c_{D}-\tau\right)^{k}\left(c_{D}^{*}-\tau\right)^{k} \\
& \Delta=c_{D}\left\{\left(c_{D}\right)^{k}\left(c_{A}^{*}\right)^{k}-\left(c_{X}^{*}\right)^{k}\left[\left(c_{A}\right)^{k}-\frac{\tau\left(c_{X}\right)^{k}}{t(k+1)}\right]\right\}+c_{D}^{*}\left\{\left(c_{D}^{*}\right)^{k}\left(c_{A}\right)^{k}-\left(c_{X}\right)^{k}\left[\left(c_{A}^{*}\right)^{k}-\frac{\tau\left(c_{X}^{*}\right)^{k}}{t(k+1)}\right]\right\} \\
& \Theta=\left[\left(c_{X}\right)^{k}\left(c_{A}^{*}\right)^{k}+\left(c_{X}^{*}\right)^{k}\left(c_{A}\right)^{k}-\frac{\tau\left(c_{X}\right)^{k}\left(c_{X}^{*}\right)^{k}}{t(k+1)}\right] .
\end{aligned}
$$

\section{Price variance}

The price variance $\sigma_{p}^{2}$ is the sum of the price variances of domestic and foreign sellers weighted with their shares in the total population of sellers:

$$
\sigma_{p}^{2}=\frac{N_{D}}{N} \sigma_{p, d o m}^{2}+\frac{N_{X}^{*}}{N} \sigma_{p, \exp }^{2}
$$

where the price variance of domestic firms is the sum of the price variances of domestic low-and high-technology firms weighted with their shares in the total population of domestic 


\begin{tabular}{l|cccc}
$\tau$ & $\left(\frac{c_{X}}{c_{D}}\right)^{k}$ & $\left(\frac{c_{X}^{*}}{c_{D}^{*}}\right)^{k}$ & $\left(\frac{c_{A}}{c_{D}}\right)^{k}$ & $\left(\frac{c_{A}^{*}}{c_{D}^{*}}\right)^{k}$ \\
\hline 1.0000 & 0.6900 & 0.7530 & 0.0739 & 0.1615 \\
0.9500 & 0.6999 & 0.7674 & 0.0746 & 0.1633 \\
0.9025 & 0.7093 & 0.7815 & 0.0753 & 0.1649 \\
0.8574 & 0.7181 & 0.7953 & 0.0759 & 0.1665 \\
0.8145 & 0.7263 & 0.8089 & 0.0764 & 0.1681 \\
0.7738 & 0.7340 & 0.8222 & 0.0769 & 0.1696 \\
0.7351 & 0.7412 & 0.8352 & 0.0774 & 0.1710 \\
\hline \hline$\tau$ & $\left(\frac{c_{X}}{c_{D}}\right)^{k} /\left(\frac{c_{X}^{*}}{c_{D}^{*}}\right)^{k}$ & $\left(\frac{c_{A}}{c_{D}}\right)^{k} /\left(\frac{c_{A}^{*}}{c_{D}^{*}}\right)^{k}$ \\
\hline 1.0000 & 0.9163 & 0.4576 \\
0.9500 & 0.9120 & 0.4568 \\
0.9025 & 0.9076 & 0.4566 \\
0.8574 & 0.9029 & 0.4559 \\
0.8145 & 0.8979 & 0.4545 \\
0.7738 & 0.8927 & 0.4534 \\
0.7351 & 0.8875 & 0.4526 \\
\hline
\end{tabular}

Table 4: Impact of a 5\%-decrease in trade costs on fraction of exporters and high-technology firms

$\left(t=0.5, k=2.5, \gamma=0.2, S=1, f=f_{E}=c_{M}=10, \psi=1.25\right)$

firms, $\frac{N_{D L}}{N_{D}}=\frac{G\left(c_{D}\right)-G\left(c_{A}\right)}{G\left(c_{D}\right)}$ and $\frac{N_{D A}}{N_{D}}=\frac{G\left(c_{A}\right)}{G\left(c_{D}\right)}$,

$$
\sigma_{p, d o m}^{2}=\frac{N_{D A}}{N_{D}} \int_{0}^{c_{A}}\left[p_{D A}-\bar{p}\right]^{2} \frac{g(c)}{G\left(c_{A}\right)} d c+\frac{N_{D L}}{N_{D}} \int_{c_{A}}^{c_{D}}\left[p_{D}-\bar{p}\right]^{2} \frac{g(c)}{G\left(c_{D}\right)-G\left(c_{A}\right)} d c .
$$

Analogously, the price variance of foreign sellers is the sum of the price variances of foreign low- and high-technology firms weighted with their shares in the total population of foreign sellers, $\frac{N_{X L}}{N_{X}}=\frac{G\left(c_{X}\right)-G\left(c_{A}\right)}{G\left(c_{X}\right)}$ and $\frac{N_{X A}}{N_{X}}=\frac{G\left(c_{A}\right)}{G\left(c_{X}\right)}$,

$$
\sigma_{p, \exp }^{2}=\frac{N_{X A}^{*}}{N_{X}^{*}} \int_{0}^{c_{A}^{*}}\left[p_{X A}^{*}-\bar{p}\right]^{2} \frac{g(c)}{G\left(c_{A}^{*}\right)} d c+\frac{N_{X L}^{*}}{N_{X}^{*}} \int_{c_{A}^{*}}^{c_{X}^{*}}\left[p_{X}^{*}-\bar{p}\right]^{2} \frac{g(c)}{G\left(c_{X}^{*}\right)-G\left(c_{A}^{*}\right)} d c .
$$

Impact of a 5\%-decrease in trade costs on fraction of exporters and high-technology firms 


\section{References}

Atkeson, A., Burstein, A., 2010. Innovation, Firm dynamics, and International Trade. Journal of Political Economy 118 (3), 433-484.

Axtell, R., 2001. Zipf distribution of US firm sizes. Science 293, 1818-1820.

Behrens, K., Mion, G., Ottaviano, G., 2007. Industry Reallocation in a Globalizing Economy. CEPR Discussion Paper No. 6049.

Bernard, A., Eaton, J., Jensen, J., Kortum, S., 2003. Plants and Productivity in International Trade. The American Economic Review 93 (4), 1268-1290.

Bernard, A., Jensen, J., 1999. Exceptional exporter performance: cause, effect, or both? Journal of International Economics 47 (1), 1-25.

Bernard, A., Jensen, J., Redding, S., Schott, P., 2007. Firms in International Trade. The Journal of Economic Perspectives 21 (3), 105-130.

Bustos, P., 2011. Trade liberalization, exports, and technology upgrading: Evidence on the impact of mercosur on argentinian firms. American Economic Review 101 (1), 304-40.

Constantini, J., Melitz, M., 2008. The Dynamics of Firm-Level Adjustment to Trade Liberalization. The Organization of Firms in a Global Economy, Harvard University Press, Cambridge.

Del Gatto, M., Ottaviano, G., Mion, G., 2006. Trade Integration, Firm Selection and the Costs of Non-Europe. CEPR Discussion Paper No. 5730.

Feenstra, R., Weinstein, D., 2010. Globalization, Markups, and the US Price Level. NBER Working Paper No. 15749.

Gorodnichenko, Y., Schnitzer, M., 2012. Financial Constraints and Innovation: Why Poor Countries Don't Catch Up. Journal of the European Economic Association, forthcoming.

Hajivassiliou, V., Savignac, F., 2007. Financing Constraints and a Firm's Decision and Ability to Innovate: Establishing Direct and Reverse Effects. London School of Economics Discussion Paper No. 594.

Hall, B., Lerner, J., 2009. The Financing of R\&D and Innovation. NBER Working Paper No. 15325. 
Helpman, E., Melitz, M., Yeaple, S., 2004. Export versus FDI with Heterogeneous Firms. American Economic Review 94 (1), 300-316.

Impullitti, G., Licandro, O., 2011. Trade, firm selection, and innovation: The competition channel. University of Cambridge, mimeo.

Irarrazabal, A., Moxnes, A., Opromolla, L., 2011. The Tip of the Iceberg: A Quantitative Framework for Estimating Trade Costs. Banco de Portugal Working Paper No. 201125.

Jaramillo, C., Lederman, D., 2006. Challenges of CAFTA: Maximizing the Benefits for Central America. The World Bank.

Keuschnigg, C., Ribi, E., 2010. Profit Taxation and Finance Constraints. CESifo Working Paper No. 2914.

Lederman, D., Maloney, W., Serven, L., 2005. Lessons from NAFTA for Latin America and the Caribbean. The World Bank.

Levine, R., 2005. Finance and growth: Theory and evidence. In: Aghion, P., Durlauf, S. (Eds.), Handbook of Economic Growth. Elsevier, Ch. 12, pp. 865-934.

Manova, K., 2010. Credit Constraints, Heterogeneous Firms, and International Trade. NBER Working Paper No. 14531.

Melitz, M., 2003. The Impact of Trade on Intra-Industry Reallocations and Aggregate Industry Productivity. Econometrica 71 (6), 1695-1725.

Melitz, M., Ottaviano, G., 2008. Market Size, Trade, and Productivity. Review of Economic Studies 75 (1), 295-316.

Navas-Ruiz, A., Sala, D., 2007. Technology Adoption and the Selection Effect of Trade. EUI Working Papers ECO 2007/58.

Ottaviano, G., Tabuchi, T., Thisse, J.-F., 2002. Agglomeration and Trade Revisited. International Economic Review 43 (2), 409-435.

Ottaviano, G., Taglioni, D., Di Mauro, F., 2009. The Euro and the Competitiveness of European Firms. Economic Policy 24 (57), 5-53.

Rajan, R., Zingales, L., 1998. Financial Dependence and Growth. American Economic Review $88(3), 559-586$. 
Rodrik, D., 2006. Goodbye Washington Consensus, Hello Washington Confusion? A Review of the World Bank's "Economic Growth in the 1990s: Learning from a Decade of Reform". Journal of Economic Literature 44 (4), 973-987.

Schnitzer, M., Buch, C., Kesternich, I., Lipponer, A., 2009. Financial Constraints and the Margins of FDI. CEPR Discussion Papers No. 7444.

Schroeder, P., Sorensen, A., 2011. Are Iceberg Trade Costs Appropriate when Firms are Heterogeneous? University of Aarhus, mimeo.

Tybout, J., 2003. Plant-and Firm-Level Evidence on "New" Trade Theories. Handbook of International Trade 1, 388-415.

Unel, B., 2011. The Interaction Between Technology Adoption and Trade When Firms are Heterogeneous. Louisiana State University, mimeo. 